Revista General de Información y Documentación ISSN: 1132-1873

http://dx.doi.org/10.5209/rgid.72818

\title{
Una documentación epigráfica inusual: el acta notarial (1747) de una inscripción medieval de la muralla de Alburquerque
}

\author{
José María de Francisco Olmos루 Rodrigo José Fernández Martínez ${ }^{2}$
}

Recibido: 7 de julio de 2020 / Aceptado: 11 de septiembre de 2020

Resumen. En este trabajo vamos a analizar el acta notarial (1747) existente en la Real Academia de la Historia, donde se dibuja y da fe de la inscripción medieval que por entonces se encontraba en la muralla de Alburquerque, veremos el motivo de su realización y compararemos su contenido con lo que se conocía hasta entonces de esta inscripción y las relacionadas con ella, hechas por los mismos protagonistas y en los mismos años (principios del siglo XIV), así como los estudios actuales de la misma.

Palabras clave: Alburquerque; Real Academia de la Historia; acta notarial; epigrafía medieval; tradición epigráfica.

\section{[en] Unusual epigraphic documentation: “acta notarial” (1747) of a medieval inscription in the Alburquerque's walls}

\begin{abstract}
The aim of this paper is to analyze an "acta notarial” (1747) found at the Real Academia de la Historia, that contains the transcription of a medieval inscription and proves its contents. That inscription, at the time that the acta was made, was placed at the Alburquerque's walls. We analyse the reason why it was made, comparing what it says with what was known at that time about the inscription and others inscriptions that had a relation with it, made by the same author and at the same time (the beginning of the $14^{\text {th }}$ century), and so with modern studies about it.
\end{abstract}

Keywords: Alburquerque; Real Academia de la Historia; medieval epigraphy; acta notarial; epigraphic historiography.

Sumario. 1. Introducción. Un acta notarial extraordinaria. 2. La Colección Diplomática de España de la Real Academia de la Historia. 3. El escudo de Alfonso Sánchez: divergencias entre la inscripción y la historiografía. 4. La copia literaria de Brás de Alburquerque y sus repercusiones. 5. La Historiografía de la inscripción tras la realización del Acta notarial. 6. Ediciones recientes y estudio de los problemas de lectura: La fecha 7. Ediciones recientes y estudio de los problemas de lectura: La

1 Universidad Complutense de Madrid. Departamento de Historia de América y Medieval y Ciencias Historiográficas

E-mail: josemafr@ucm.es

2 Universidad Complutense de Madrid. Departamento de Historia de América y Medieval y Ciencias Historiográficas

E-mail: rodfer04@ucm.es 
suscriptio del Maestre del Castillo. 8. El Acta Notarial de 1747. 9. Nueva Lectura y edición de la inscripción. 10. Conclusiones. 11. Referencias Bibliográficas.

Cómo citar: Francisco Olmos, J. M. de; Fernández Martínez, R. J. (2020) Una documentación epigráfica inusual: el acta notarial (1747) de una inscripción medieval de la muralla de Alburquerque, en Revista General de Información y Documentación 30 (2), 473-506.

\section{Introducción. Un acta notarial extraordinaria}

Como parte de los trabajos realizados dentro de diversos proyectos de investigación en curso donde intervienen los miembros del Grupo de investigación NUMISDOC, de la Universidad Complutense de Madrid, como son los del Corpus Inscriptionum Hispaniae Mediaevalium ${ }^{3}$, y el de recogida de documentación sobre el patrimonio epigráfico documental de la Comunidad de Madrid ${ }^{4}$; uno de los cuales es la revisión historiográfica de las diferentes ediciones de las inscripciones medievales realizadas por estudiosos de la época medieval y moderna, nos encontramos en la Colección Diplomática de España, conservada en la Real Academia de la Historia, un acta notarial totalmente extraordinaria, que nos informaba de una inscripción localizada en las murallas de la villa de Alburquerque y que en este trabajo analizaremos por su extraordinario interés como un documento único en cuanto a sus aspectos formales y de contenido ${ }^{5}$.

El acta fue realizada por Manuel Díaz Lucio, "escribano del Rey nuestro Señor Público y de los del número de esta villa de Alburquerque”, y en ella hace una copia figurativa de una inscripción que se encontraba por entonces en las murallas de esa

3 El proyecto del Corpus Inscriptionum Hispaniae Mediaevalium se constituyó formalmente en 1995, y dirigido por los profesores de la Universidad de León Vicente García Lobo y María de la Encarnación Martín López, ha aglutinado a diversos especialistas españoles y extranjeros para realizar tareas de recopilación, recuperación, reconstrucción y puesta en valor de los textos epigráficos de época medieval emplazados en el territorio español. Actualmente el proyecto avanza en la publicación de los estudios epigráficos por provincias, contando con varios volúmenes editados, así como distintas monografías, realización de congresos y seminarios especializados y fomento de diferentes tesis doctorales. En la actualidad está avalado por un proyecto concedido en la convocatoria del Plan Nacional de Investigación, del Ministerio de Ciencia, Innovación y Universidades, Convocatoria Proyectos I+D+i 2019 Retos de la Sociedad (PID2019-104395RBI00 HIS).

4 Este proyecto H2019/HUM-5742, titulado Archivo virtual para las investigaciones sobre el Patrimonios Epigráficos Medievales de la Comunidad de Madrid- AVISPES-CM, está financiado por la Comunidad de Madrid y está compuesto por varios grupos de investigación de distintas Universidades de la Comunidad de Madrid.

5 Real Academia de la Historia (RAH), Colección Diplomática de España, Colección Litológica, Legajo $n^{\circ} 1$ (11/9211), Alburquerque (2).

6 En estos años Alburquerque era una villa de señorío, como confirma el Catastro de Ensenada (11 de junio de 1753), que nos dice que “pertenece a la Casa y Estados del Duque de Alburquerque”, que desde 1733 era don Francisco Nicolás Fernández de la Cueva, XI Duque, que residía en Madrid, donde fue Caballerizo Mayor del Príncipe Fernando (1742), puesto que mantuvo al ascender al trono como Fernando VI (1746), y además el monarca le otorgó el Toisón de Oro (7de octubre de 1746). Renunció al cargo palatino por razones de salud (1749), aunque mantuvo la cercanía al monarca y el acceso a la Real Cámara hasta su muerte en 1757. A su muerte el título y mayorazgo ducal pasó a un pariente colateral Pedro Miguel de la Cueva Velasco y Guzmán, Mariscal de Campo (m.1762), al que heredó su hijo, Miguel José de la Cueva Velasco y Guzmán, Caballero del Toisón (1789) (m.1803), durante cuyo gobierno se harán varias recopilaciones históricas y geográficas sobre la villa de Alburquerque, que luego comentaremos, coincidiendo con la realización del famoso Diccionario Geográfico de Tomás López. 
villa y "certifica y da fe" de la autenticidad de los caracteres copiados, todo sobre un pliego oficial doble de papel sellado (sello quarto), fechándola el día 20 de diciembre de $1747^{7}$.

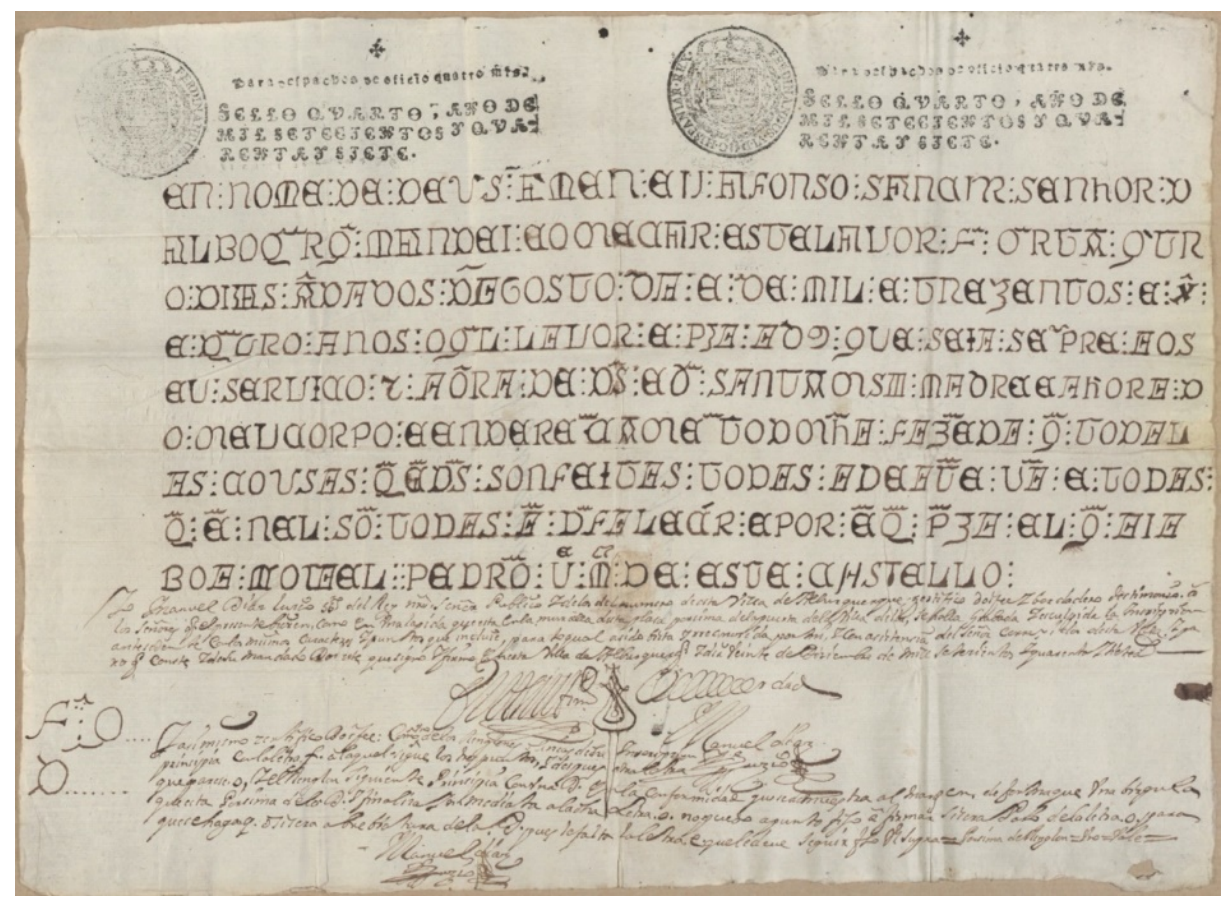

Figura 1. Acta notarial sobre la inscripción de la muralla de Alburquerque (1747).

(C) Real Academia de la Historia.

En las siguientes líneas vamos a intentar desvelar el porqué de esta acta notarial y su importancia como fuente para el estudio de la epigrafía y, particularmente para la epigrafía de la región. Además, analizaremos la forma en la que se ha ido transmitiendo la inscripción a través de la historiografía poniendo especial atención en las divergencias existentes sobre cómo atienden a los elementos externos e internos de la inscripción y cómo estos realmente son. A partir de este análisis, ofrecemos una nueva propuesta de lectura de la inscripción desde una metodología propia de la Epigrafía Medieval que dé solución a las carencias que poseen las hasta ahora ofrecidas.

7 Yo Manuel Diaz Luzio escribano del Rey nuestro señor público y de los de numero de esta villa de Albuquerque. Zertifico doi fee e berdadero testimonio a / los señores que el presente bieren como en una lapida que esta en la muralla desta plaza porsima de la puerta de la villa della se halla grabada y esculpida la inscripcion / antesedente con los mismos caracteres y puntos que incluye, para lo cual a sido vista y rreconoscida por mi y con asistensia del señor corregidor desta villa y pa/ra que conste y de su mandado por este que signo y firmo en esta villa de Albuquerque a dia veinte de diziembre de mill setezientos y quarenta y siete años. (FIRMA Y SIGNO). Con un añadido posterior que detalla algunos problemas de lectura que luego comentaremos. 


\section{La Colección Diplomática de España de la Real Academia de la Historia}

Entre los objetivos que la Real Academia de la Historia tuvo desde su fundación (1738) estaba la realización de una Historia de España basada en fuentes ciertas y fidedignas. Por ello, no tardó en comenzar a recopilar desde sus inicios documentos (originales y copias) que pudieran ayudar a conseguir este objetivo, y dentro de este interés por las fuentes primarias empezó a formar una interesante colección monetaria y también propuso y consiguió que se copiaran numerosas inscripciones antiguas y medievales para formar un corpus que sería la base de una historia de España epigráfica o litológica, como a veces se denominaba también a estas fuentes.

En estos primeros años de actividad de la Academia aparecen dos personajes, Antonio Mateos Murillo ${ }^{8}$ y Francisco de Rivera ${ }^{9}$ que fueron los protagonistas de impulsar un proyecto de recopilación de fuentes históricas, en principio realizado bajo la tutela de la Academia, pero el proyecto pronto excedió, en fondo y magnitud,

8 Según los datos del Diccionario Biográfico de la Real Academia de la Historia (2020) http://dbe.rah.es/biografias/20234/antonio-mateos-murillo [Consulta 21/02/2020]., y del Anuario de la institución, podemos decir que nació en Jerez de la Frontera (1721), fue presbítero y se licenció en leyes en la Universidad de Granada con una beca del Colegio de San Bartolomé y Santiago, siendo recibido como Abogado en la Real Audiencia de Sevilla y poco después en Madrid (1740). Su pasión por la Historia le hizo entrar en la Academia como miembro honorario (1753), luego como supernumerario (1754) y por último como individuo de número (1759), ocupando años después los cargos de censor (1774-1787), tesorerorecaudador (1787-1791) y también fue su primer bibliotecario (1787-1791). Fue un activo miembro de los trabajos de la Academia, participó en diversas comisiones y escribió varios trabajos de interés sobre temas cronológicos y altomedievales. Fue también miembro de la Real Academia Española, primero como supernumerario (1773) y luego como numerario (1775) ocupando el sillón R. Murió en Madrid el 19 de noviembre de 1791 .

9 Según los datos del Diccionario Biográfico de la Real Academia de la Historia (2020) http://dbe.rah.es/biografias/23772/francisco-de-rivera [Consulta 21/02/2020] sabemos que entró en el Servicio Real hacia 1742, formando parte del contingente que luchó en Italia en esos años, según su testamento (9 de julio de 1788 ante Juan Pedro Sierra) sabemos que Rivera había nacido en Palermo (Sicilia), hijo de Josef de Rivera, capitán de Caballería, y de Isabel de Nicoló. Luego fue profesor de Filosofía y Matemáticas del Colegio de Caballeros Pajes de Madrid. Entró como miembro honorario en la Real Academia en 1746 (26 de septiembre), pasando poco después a numerario (15 de diciembre de 1747) desempeñando las funciones de revisor, y siendo muy activo en diversas tareas académicas, donde elaboró un interesante proyecto para hacer una Historia Universal y Geografía de las Indias, que fue presentado en la Junta de la institución en 1756. Entre 1764 y 1769 el cargo de anticuario estuvo vacante y se decidió que se encargaran de la custodia y trabajos del monetario Luis José Velázquez y Francisco de Rivera, que adquirieron importantes lotes de libros de numismática y antigüedades para realizar los trabajos de catalogación y ordenación del mismo, además Rivera, vendió a la Academia una importante pieza, el cincuentín de plata de Felipe IV, y colaboró en la compra de otras importantes piezas numismáticas (Maier Allende, 2011: 64-65). También realizó varios informes, como la certificación del peso, ley, valor y el nombre de los grabadores de cuños de dos medallas de proclamación de Fernando VI remitidas a la Academia en marzo de 1763. En la Corte ejerció diversos cargos económicos, en especial como Contador de la Real Casa de la Moneda de Madrid, donde escribió una interesante obra (de Rivera, 1779), en cuya portada aparece intitulado como "D. Francisco de Rivera, del Consejo de S.M. su secretario y contador de la Real Casa de Moneda de Madrid”, siendo además también miembro de la Real Junta de Comercio y Moneda. Murió en Madrid el 24 de diciembre de 1788, dejando como heredera de todos sus bienes a su esposa María de la Fuencisla Fernández del Pozo. Sabemos que Rivera tenía intereses en la provincia de Badajoz, ya que existe constancia de un "Recurso del pleito entre Juan Manuel Andia, vecino de la villa de Cabeza del Buey (Badajoz), y Francisco Rivera, vecino de Madrid, contra el conde de Superunda (Diego Antonio Manso de Velasco y Crespo Ortega, II Conde de Superunda, al convertirse en heredero de su tío, el I Conde (1748), José Antonio Manso de Velasco y Sánchez de Samaniego, caballero de Santiago, teniente general, Gobernador de Chile y Virrey del Perú), sobre aprovechamiento de pastos en la dehesa de la Serena” (Archivo Histórico Nacional (AHN), Consejos, 31494, Exp.1, expediente realizado entre 1773 y 1775). 
los planes que había diseñado la institución, y cuando la Academia decidió no continuar con esta labor ambos individuos continuaron la tarea sufragando personalmente los gastos que se iban produciendo, creando un importante conflicto que tuvo que llegar al arbitraje regio. En 1767 el Marqués de Grimaldi trasladó a los interesados que el Monarca, Carlos III, aplaudía el desinterés que habían demostrado negándose a admitir el reembolso por parte de la Academia de las sumas que ambos tuvieron que abonar para recoger los documentos de la Colección, ordenando asimismo que se les tuviera presentes "para remunerarlos y adelantarlos dignamente en sus respectivas carreras" y previno a la Academia de que anotase en sus Actas todo lo dispuesto por el Rey y encargarse de nuevo a Murillo y Rivera la continuación de "tan recomendable obra". Es en este año de 1767 cuando la llamada Colección de Monumentos Históricos pasó a custodiarse en la Biblioteca de la Academia ${ }^{10}$. Hoy en día esta Colección cuenta con aquellos volúmenes depositados en 1767 (con un índice y plan de la obra en su inicio), pero ambos individuos siguieron trabajando en el proyecto, y en 1773 ingresaron 325 volúmenes y en 1792 otros 185 volúmenes, formando varias series o Colecciones, como la Colección Diplomática de España, la Colección Heráldica, Arqueológica, Iconográfica, Litológica, Numismática, Bibliográfica, Kalendario, Cronicones, Arboles Genealógicos, Misceláneas Históricas, Memoriales ajustados, Colección de Pleitos, etc. (Alberola Fioravant, 1995: 50).

Sobre la Colección Litológica hay que decir que la forman siete legajos ordenados de forma alfabética por el lugar donde se encontraba la inscripción recogida en ellos, y en su totalidad, salvo el acta notarial comentada, son todo noticias y documentos recogidos mediante "recortes de obras impresas o copiadas a mano cuando no se dispone de ejemplares para recortar". Lo cual a nosotros nos causa pavor, ya que se utilizaron abundantes libros que fueron mutilados de todos sus datos epigráficos ${ }^{11}$ para luego pegarlos sobre papel con la referencia del libro del que provienen.

De esta manera al llegar a Alburquerque, encontramos recortado y pegado en una hoja el dato que ofrece sobre la inscripción de la muralla de la villa el libro de Gonzalo Argote de Molina (1588: 90-90v), donde el autor, al hablar de los Señores de Alburquerque, en concreto de Doña Teresa de Meneses, comenta que casó con don Alfonso Sánchez, hijo bastardo del Rey don Dinis de Portugal, y a continuación

10 Más datos sobre esta Colección en las biografías de ambos personajes en el Diccionario Biográfico de la Real Academia de la Historia, realizadas por Teresa Nava Rodríguez, donde cuenta también con cierto detalle algunos de los problemas surgidos en la realización de este trabajo, como el memorial enviado por Felipe Varela Bermúdez (11 de septiembre de 1767), donde este vecino de Madrid acusaba a ambos de no haberle devuelto diversos memoriales, discursos y libros que él les había prestado para hacer uso de ellos en su colección y "sólo para que los disfrutase el Cuerpo no aquellos individuos". Pero tras el explícito apoyo del Rey a su labor y las órdenes recibidas desde la Corte, el secretario, Lorenzo Diéguez y Ramírez de Arellano, informó de todo al Director, Pedro Rodríguez de Campomanes, y añadió esta anotación "atendidas las circunstancias críticas del asunto por no indisponerlo mas, dispuso que se suspendiera dar cuenta a la Academia en Junta de oi 18 de septiembre de 1767”.

11 Y lo mismo ocurre en la colección numismática y en otras de este trabajo que comentamos, que están formadas por recortes de libros. 
detalla sus armas diciendo que se ven en la puerta del Castillo de esta villa ${ }^{12}$, que él edificó y en las murallas de ella, para terminar diciendo: "Y en la muralla de la dicha villa de Alburquerque se ve un letrero que dice assi” (figura $\mathrm{n}^{\circ} 2$ ).

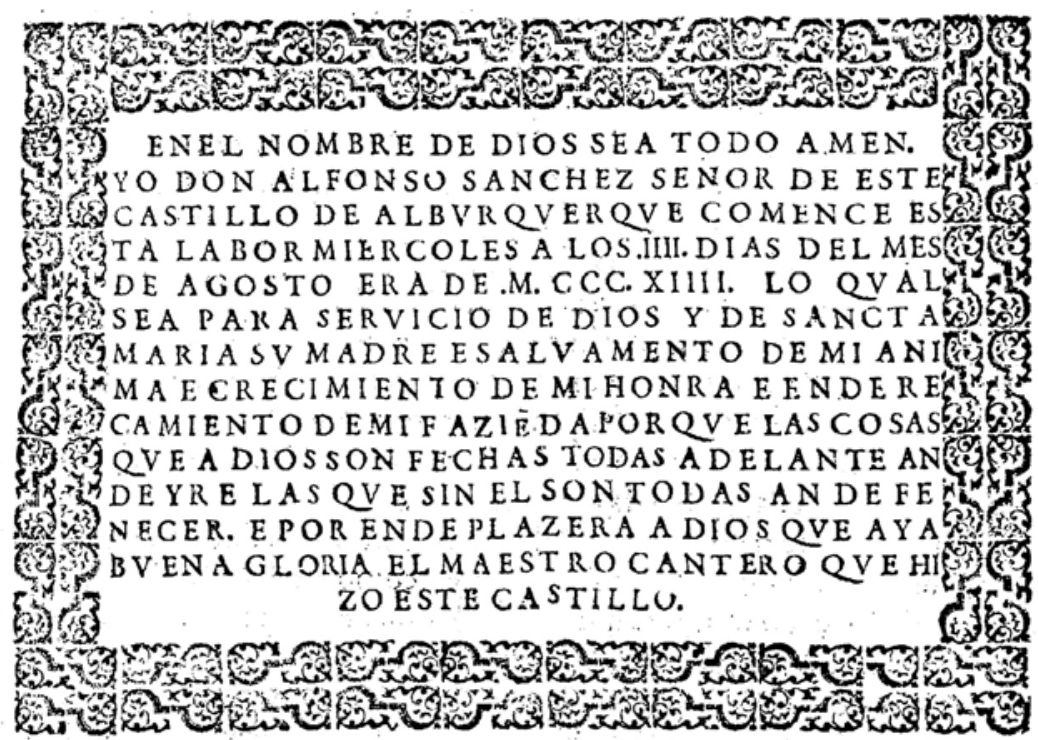

Figura 2. Inscripción de la muralla de Alburquerque (Argote de Molina, 1588: 90v.).

E inmediatamente después aparece doblada el acta notarial que estamos comentando. Sin más datos que su texto, ya que en el reverso sólo aparece escrito en dos ocasiones la palabra Alburquerque.

\section{El escudo de Alfonso Sánchez: divergencias entre la inscripción y la historiografía}

La inscripción protagonista de esta acta notarial ya era bien conocida en 1747, como luego veremos en su historiografía, pero es aquí donde empiezan los problemas, ya que tanto la descripción de las armas de Alfonso Sánchez, como el texto y estructura de la inscripción de la muralla que nos ofrece Argote de Molina

12 El escudo que comenta Argote de la puerta del Castillo, podría ser el que se encuentra en la Puerta de Valencia de la villa, cuya inscripción parece hoy ilegible, o bien el que en origen estaba en la Puerta de Alcántara, y que luego pasó al Ayuntamiento, y hoy se encuentra, como material reaprovechado, embutido en los muros del recinto de la Plaza de Armas del castillo, enfrente de la Iglesia, y que tiene una inscripción a su alrededor. Esta inscripción, que Argote no parece conocer, cuyo texto dice (traducido y actualizado) que, en la Era de 1314 años, el día 7 de agosto, fue comenzado este Castillo de Alburquerque, por don Alfonso Sánchez, señor de este lugar. Este texto fue leído y estudiado desde principios del siglo XX, pero la transcripción y estudio completo fue hecho por primera vez por José Maria Cordeiro de Sousa (1946: 449-460), y luego por Mario Jorge Barroca (2000: 1403-1408). Al hablar de la inscripción de la muralla volveremos a comentar algunas cosas sobre ella, ya que ambas están relacionadas. 
no se corresponden con la realidad, y en las obras de la época no encontramos ninguna referencia explícita que mencione estas discrepancias. En este apartado abordaremos las diferencias existentes entre la composición heráldica ejecutada sobre la inscripción y las descripciones hechas de la misma intentando explicar su origen, para seguidamente abordar las cuestiones referentes al texto de la inscripción.

Creemos que Gonzalo Argote de Molina, desgraciadamente bien conocido por sus imprecisiones en el uso de las fuentes, cuando no fabulaciones, nunca vio directamente el epígrafe que estaba comentado y copió los datos de la primera publicación de esta inscripción, realizada por Brás de Albuquerque ${ }^{13}$ (1576: 576) (1774: 252-254), quien dice que en la puerta principal de la villa están puestas sus armas, y dibuja el escudo (figura $\mathrm{n}^{\circ} 3 \mathrm{a}$ ), mostrando en su parte superior una especie de asa, que también se ve en los escudos originales que se conservan en la villa de Alburquerque. Pero lo que llama la atención de los escudos que aparecen en los libros de Albuquerque y Argote (figura $\mathrm{n}^{\circ} \mathrm{3b}$ ), que muestran las mismas armas, es que su diseño no se corresponde con la realidad heráldica de los mismos.
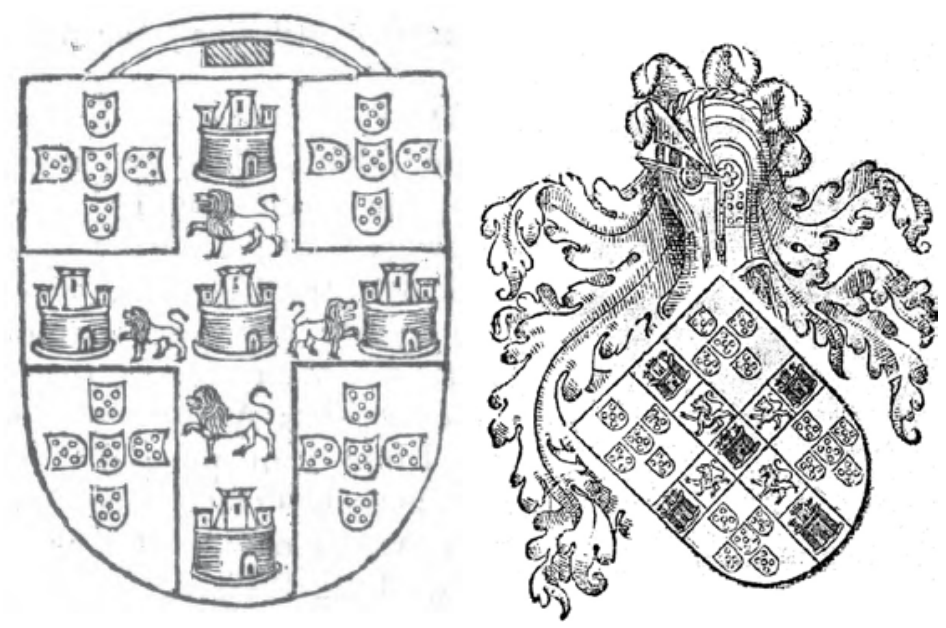

Figura 3. Escudo de Alfonso Sánchez según el diseño de Brás de Albuquerque (1774: 253) y el de Gonzalo Argote de Molina (1588: 92).

En la villa de Alburquerque existen al menos otros dos escudos de Alfonso Sánchez, el que está en el centro de la inscripción que estamos comentando, que

13 Afonso Brás de Albuquerque (h.1500-1580), fue un escritor e importante humanista, hijo natural de Alfonso de Alburquerque (1453-1515) el célebre almirante y virrey de la India portuguesa, al que legitimó en 1506, y poco antes de morir pidió al rey Manuel I que le protegiera y se ocupara de su formación, y así lo hizo el monarca, además de casarle con María de Noronha, hija del conde de Linhares, fue veedor de Hacienda con Juan III, Presidente del Senado de Lisboa (1569) y autor del libro donde aparece por primera vez el dibujo del escudo y los datos de la inscripción de la muralla de Alburquerque, finalizando con ellos, de hecho, la obra (Brás de Alburquerque, 1557) y que tuvo una segunda edición corregida y muy aumentada (Brás de Alburquerque, 1576), a su vez, reeditada en cuatro tomos (Brás de Alburquerque, 1774) por la Regia Officina Typografica de Lisboa. 
actualmente se encuentra en la plaza de armas del Castillo (figura ${ }^{\circ} 4$ ) con el texto ya comentado fechado en 1314, y el que está sobre la Puerta de Valencia, con una inscripción ilegible a su alrededor, y todos tienen ese característica "asa" en su parte superior ${ }^{14}$, aunque los de la plaza de armas y la Puerta de Alcántara la colocan en el interior del campo del escudo ${ }^{15}$, mientras el de la inscripción de la muralla se ve perfectamente sobre dicho campo, que vemos que el autor portugués refleja fielmente en su dibujo. El escudo de nuestro personaje aparece también en las miniaturas del famoso Libro de la Coronación de los Reyes de Castilla ${ }^{16}$.
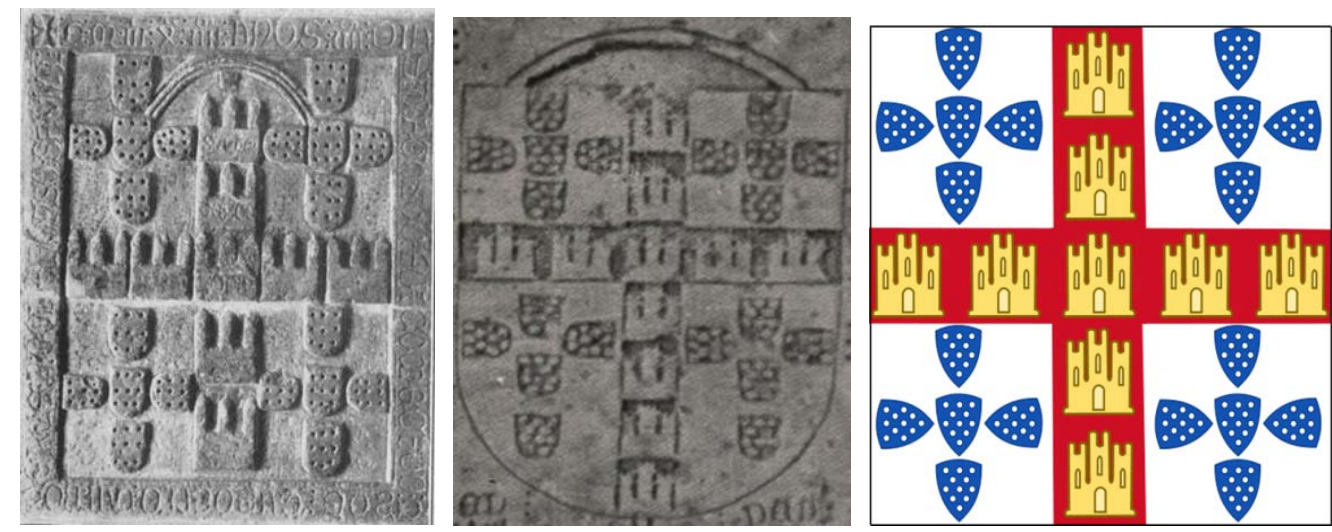

Figura 4. Escudos de Alfonso Sánchez, señor de Alburquerque, de la plaza de armas del castillo, de la inscripción de la puerta de San Mateo, y diseño del Libro de la Coronación.

14 Este diseño de escudo, denominado en Portugal em cadeado, es usado de forma muy abundante entre los reinados de Alfonso III y Pedro I, y no tiene ningún significado especial, es sólo una moda artística que tuvo éxito. Asunción Delgado Serrano nos dice que es un escudo pequeño y redondeado, y que a modo de corona, tiene un doble sector de circunferencia sobre el jefe; de la barba sale una pequeña punta, al parecer de cruz acolada (Delgado Serrano, 1950: 10). Este “adorno” nos recuerda a los que aparecen en los más antiguos escudos heráldicos, el llamado tiracol, una correa que servía para colgar los escudos de la pared, de una sepultura o de cualquier otro lugar (Menéndez Pidal, 2014: 128).

15 Barroca relaciona los dos escudos cuadrangulares de Alfonso Sánchez, tanto en su forma como en su leyenda y datación (1314), dando para ello, además de otros argumentos uno heráldico. Basándose en el estudio que el Marqués de Abrantes hizo de las imágenes que aparecen en el Libro de la Coronación de los Reyes de Castilla del Monasterio del Escorial, declaraba que la bandera de Alfonso Sánchez allí representada en el séquito que acompañaba a Alfonso XI, usa esta forma cuadrada, indicando que dicha forma parece estar reservada por entonces a los “Grandes” del reino (aparece en el folio 7 de la obra junto a las armas de los Lara, los Haro y los infantes Pedro y Felipe, hijos de Sancho IV), considerándose a nuestro protagonista como uno de ellos, tanto por su linaje como por sus señoríos y sus cargos, pues era mayordomo mayor del rey de Portugal (Barroca, 2000: 1408-1409). Para más información (Abrantes, 1982: 79-90).

16 El Libro de la Coronación de los Reyes de Castilla (Real Biblioteca de El Escorial, Cód. \& iii-3) es un códice que reúne dos ordines de coronación pertenecientes, respectivamente, a los reyes de Castilla y de Aragón. El primero fue preparado para la coronación y unción de Alfonso XI de Castilla, que tuvo lugar en 1332, tratándose de la única pieza conservada de similares características para un rey de Castilla. Recogiendo una interesada adaptación del Ordo de coronación imperial, llamado de Constantinopla, quedó inacabado en texto y miniatura, tras la ceremonia de toma de armas. En él aparecen numerosas miniaturas con interesante heráldica, y la importancia de nuestro personaje se demuestra en que sus armas, aparecen junto a la de otros grandes magnates castellanos, como los Lara y los Haro. 
Este detalle podría indicarnos que Brás de Albuquerque vio realmente el escudo que aparece en su libro, pero llama la atención el hecho de que su dibujo no concuerda con la realidad, ya que la cruz central del mismo la rellena alternando los castillos y leones del escudo real castellano-leonés, y lo mismo hace Argote de Molina, que incluso los describe en detalle ${ }^{17}$, mostrando así la relación de Alfonso Sánchez con la Casa Real de Portugal, ya que era hijo bastardo del rey Dionisio, de hecho parece que su preferido; y con los reyes de Castilla-León ya que su mujer, Teresa Martins, propietaria de la villa de Alburquerque, era nieta por su madre del rey Sancho IV ${ }^{18}$. Pero la realidad es que viendo los escudos originales realizados en piedra en Alburquerque se aprecia claramente que los leones que se comentan no existen, en la cruz del escudo sólo hay castillos, en número variable, según la cruz adopta la forma de cruz griega o de cruz latina ${ }^{19}$, lo cual se reafirma al ver los sellos originales de Alfonso Sánchez y su mujer (Figura $\left.n^{0} 5\right)^{20}$.

17 "que son en campo de plata una Cruz, que atraviessa todo el Escudo, y en ella nueve iaqueles con cinco Castillos de oro en campo roxo, y quatro Leones Roxos en campo de Plata, y en los quatro quarteles de el Escudo, cinco Escudos de las Reales Quinas de Portugal, que son azules con Quinas de Plata” (Argote de Molina, 1588: 90).

18 Menéndez Pidal de Navascués nos comenta esta relación familiar y el sello que usó en 1318, donde aparecen las señales propias de doña Teresa Martins, las lises son de los Soverosa, linaje de su abuela paterna (de quien también tomó el nombre), y los leones serían los propios de la familia de su madre, el león del linaje real de Sancho IV (Menéndez Pidal de Navascués, 2011: 205-206).

19 Sousa nos dice que este mismo diseño heráldico aparece en la Cruz relicario de cristal de roca y plata que don Alfonso regaló al monasterio de Santa Clara de Vila-do-Conde (hoy en el Museo de Arte Antiguo de Lisboa), pero añade que en una piedra armera existente en el palacio Quinta da Bacalhoa, en el pueblo de Azeitao (antigua propiedad de la Casa Real que fue adquirida en 1528 por el escritor Brás de Albuquerque, que la reconstruyó de forma magnífica), el número de castillos de la cruz se redujo a cinco, colocando entre ellos cuatro leones, mientras que en las quinas el número de besantes se redujo también a cinco (Sousa, 1946: 451). Sin embargo, en el túmulo de don Alfonso en el monasterio de Santa Clara de Vila-do-Conde, que sustituyó al primitivo en el siglo XVI, se mantuvo el diseño tradicional, sin leones, probablemente copiando el escudo que hubo en el túmulo original del siglo XIV. Sobre el diseño de su escudo (Barroca, 2000: 1308), donde se cita en especial el estudio de sus sellos, que confirma el uso de un modelo igual al que aparece en las inscripciones de Alburquerque. En nuestra opinión, la piedra armera de la Bacalhoa, de factura totalmente similar a la que hemos comentado del libro de Brás de Albuquerque, debió de ser realizada por el mismo escritor, de ahí sus cambios de diseño.

20 Remitimos a la obra de Antonio Caetano de Sousa (1783) donde encontramos los sellos en la Lámina G del libro IV, y se explican en el capítulo II del Libro V, (1783: 23-24), donde se dice que son de cera roja, y se encuentran pendientes de una carta de venta por la cual el matrimonio vende al rey Dinis la fortaleza de Campo Mayor, datada el 18 de octubre de 1318. Sobre estos sellos ver también (Abrantes, 1983: 259-260) y (Delgado Serrano, 1950: 10-12). 

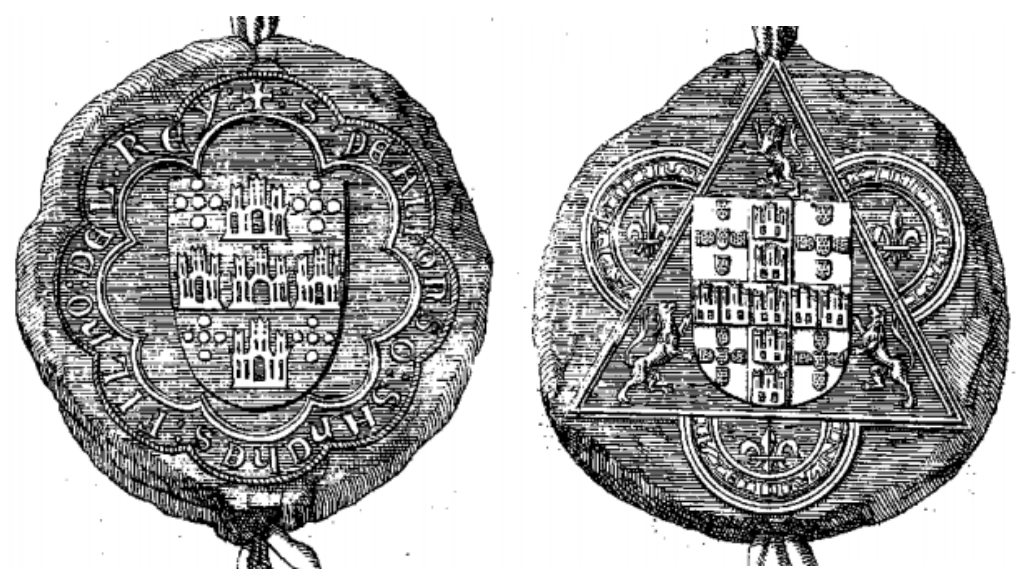

Figura 5. Sellos de Alfonso Sánchez, señor de Alburquerque (que aparece en la leyenda como hijo del rey), y de su mujer, Teresa Martins, que lleva las armas del marido en el centro, rodeado por sus señales de lises y leones.

Hay otras pequeñas anomalías de diseño, entre los originales y los dibujos del siglo XVI, tales como la ordenación de las quinas portuguesas ya que en los originales el interior de los escudetes que las forman tienen un sembrado de besantes que era la forma antigua de su diseño, mientras que en el dibujo de Brás de Albuquerque siempre aparecen en ellos solo cinco puntos colocados en aspa, que era la forma más moderna de realizar las quinas, un nuevo modelo iconográfico que se fue fijando con el tiempo, en especial desde el establecimiento de la Casa de Avís en el trono portugués (1385). Esta “actualización” del diseño de las quinas no es importante en sí misma, ya que el autor buscaría que el lector reconociera las quinas tal y como se hacía en su época, lo más grave fue la introducción de los leones en la cruz, algo que sí cambiaba de forma radical el modelo original de las armas de Alfonso Sánchez. El motivo del uso de este incorrecto diseño no lo sabemos, pero es muy curioso, por una parte podría deberse a que los escudos estaban a gran altura y que el autor no pudo verlos con el suficiente detalle, o bien su informante se equivocó al darle los datos, o simplemente, como miembro de la familia no necesitaba que le dijeran cómo era el escudo de su linaje, ya que lo conocía perfectamente (o eso creía), por lo cual optó por realizarlo en la forma que él creía ser la verdadera, extrapolando los datos del siglo XVI a principios del siglo XIV. En cualquier caso queda evidenciado que Argote de Molina copió la heráldica al autor portugués y por tanto repitió su error sin comprobar la fuente ${ }^{21}$.

21 La única diferencia entre el diseño de los escudos de Bras de Alburquerque y Argote de Molina es el sentido de la marcha de uno de los leones de la cruz, de nuevo algo no fundamental. Mientras que Bras busca la simetría y el efecto estético, Argote quiere mantener a toda costa el diseño formal del león del escudo real y su orden de marcha, siendo estas dos posturas en la representación heráldica muy utilizadas desde la Baja Edad Media hasta los inicios de la Edad Moderna, cuando se impuso la segunda por entender que no cabía variar en nada el diseño de las armerías, aun cuando fuera para mejorar la estética de la composición, reforzando la 


\section{La copia literaria de Brás de Alburquerque y sus repercusiones}

Tras mostrarnos el escudo de Alfonso Sánchez, en la versión que él creía correcta, Brás de Albuquerque nos dice que en la misma puerta donde se situaba el escudo estaba puesto este letrero, que en la edición de 1774 se ofrece con algunas ligeras variantes de lectura ${ }^{22}$ :

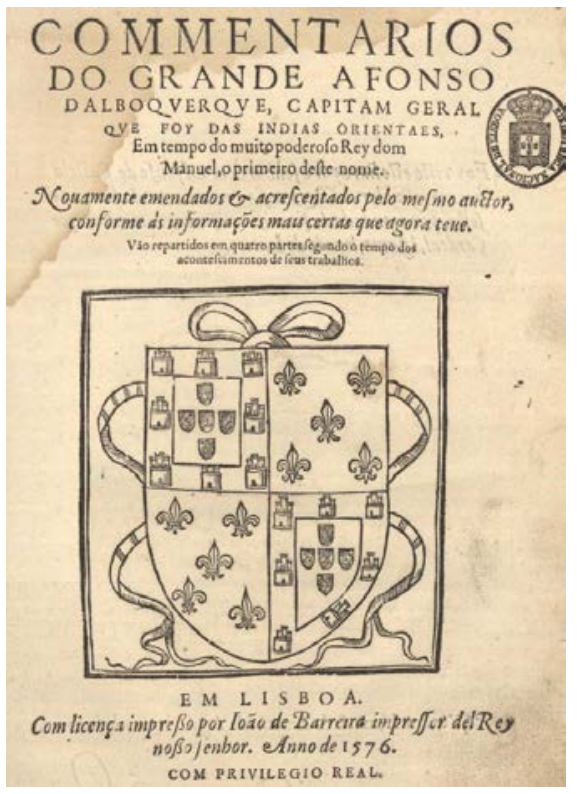

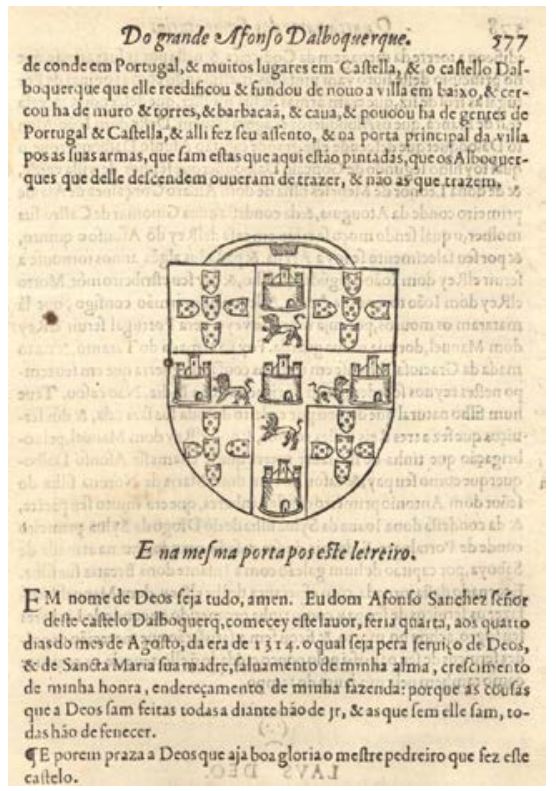

Figura 6. Portada del libro de Brás de Alburquerque (1576) y detalle de la inscripción.

ideas de unas “reglas” heráldicas inamovibles, lo cual causó muchas malas interpretaciones posteriores cuando se han estudiado diseños heráldicos medievales que sí primaron los criterios estéticos sobre los formales. Sobre este tema del diseño ver los trabajos de Faustino Menéndez Pidal de Navascués (1993) y (2014).

22 Obsérvese el escudo de la portada del libro, un cuartelado de las quinas de Portugal con las lises de Francia, que es el diseño adoptado por el hijo y heredero de Alfonso Sánchez y Teresa Martins, el famoso Juan Alfonso de Alburquerque (m.1354), señor de Alburquerque, Codosera, Medellín y Alconchel, del que dice el autor "foi grande Senhor en Castella, e o primeiro que tomou este appellido Dalboquerque: edificou a torre da menagem da Codiceira, en ella poz as suas Armas, que no principio desde Livro van pintadas, misturando com as quinas de Portugal as Flor de Liz, que eran Armas de sua mulher, que descendiam da Casa Real de França, que os Alboquerques agora trazem” (Brás de Alburquerque, 1774: 254). Este señor fue con Alfonso XI mayordomo mayor de la Reina (1331-1332), Alférez Real (1333-1336), a quien el monarca daba en las cartas el tratamiento de don, propio de los ricoshombres de Castilla, fue además ayo y mayordomo mayor del infante Fernando (1333), y luego de su hermano Pedro (1339-1347), y cuando éste se convirtió en rey Pedro I, fue mayordomo mayor de la Reina (1351) y canciller mayor del Rey (1351-1352), siendo el principal consejero y privado del monarca en los inicios del reinado. Casó con su pariente Isabel Alfonso de Meneses, hija de Tello Alfonso de Meneses (m.1315, hijo de Alfonso Téllez de Meneses, con quien en 1308 Alfonso Sánchez había intercambiado la mitad del señorío de Alburquerque por la villa de San Felices), señor de Meneses, Montealegre, Tiedra, Grajal de Campos, Alba de Liste, San Román, Villagarcía de Campos, San Felices, etc. y de María de Portugal (hija del Infante Alfonso de Portugal, señor de Portalegre, hermano menor del rey Dinis; y de Violante Manuel, hija del Infante Manuel de Castilla y medio hermana de Don Juan Manuel), que heredó todas las posesiones paternas tras la temprana muerte de su hermano. Más datos en (de Salazar y Acha, 2000). 


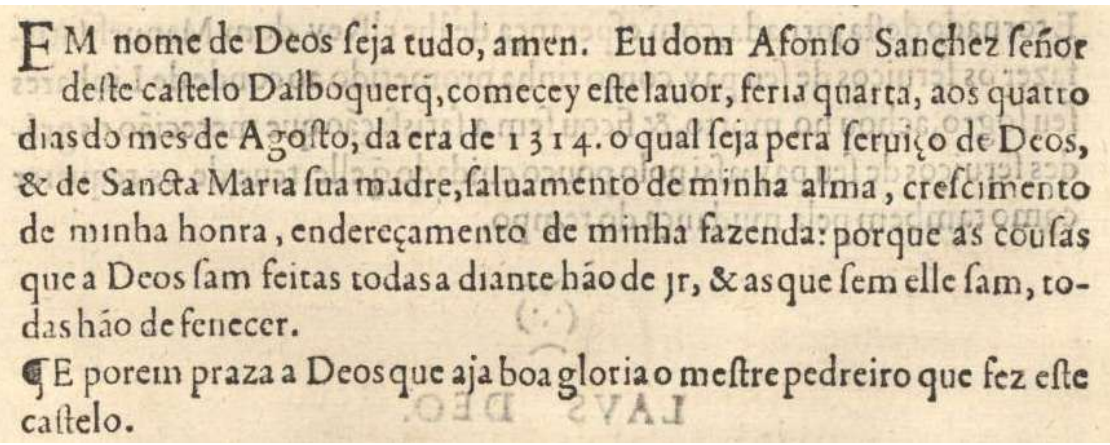

Figura 7. Lectura ofrecida por Brás de Alburquerque en la edición de $1576^{23}$.

Como vemos es un texto realizado en portugués, como la inscripción original, que el autor desarrolla de la manera que cree más conveniente para darle sentido, no dice nada de que el escudo esté en el centro de la inscripción ni de los problemas de lectura de diversas partes de la misma ni tampoco de la fecha (problema Era/Año). Si comparamos el texto con el que da Argote de Molina vemos que el autor español se limita a hacer una simple traducción del mismo, cambiando incluso el "feria quarta" del original por "miércoles", tal vez para que los lectores castellanos entiendan mejor el sentido, aunque alteraba claramente el contenido, mientras el resto de la traducción es de lo más literal, tal vez incluso excesivamente literal en algunas partes, cuando lo correcto hubiera sido dejar el texto en portugués y añadir su traducción. Con todo lo anterior podemos afirmar que Argote tomó los datos del escudo y la inscripción del libro de Brás de Albuquerque, escrito unos años antes, sin cotejar los mismos con el original que todavía se encontraba en la villa, y por ende mantuvo los errores del primero, añadiendo de su cosecha el texto de esta inscripción como si estuviera escrita en castellano, cuando el original estaba en portugués, cambiando además algunas palabras.

Pero la interpretación de Argote fue un éxito, así unos años después, Fr. Francisco de Brandao, al tratar de Alfonso Sánchez, dice que como memoria de sus obras en la villa de Alburquerque queda una inscripción ya publicada por Argote de Molina, y a continuación copia el texto de la misma según la versión castellana (de Brandao: 1672, 153), no conociendo que se ajustaba mucho más a la realidad la versión que años antes había copiado su compatriota Brás de Albuquerque, lo cual llama la atención en un autor portugués de su categoría ${ }^{24}$. Estas tres publicaciones

23 En la edición de 1774 la lectura es la siguiente: Em nome de Deos seja tudo. Amen. Eu Dom Afonso Sanches Senhor desde Castello Dalboquerque, comecei este lavor, feria quarta, aos quatro días do mez de Agosto, da era de 1314, o qual seja pera serviço de Deos, e de Sancta Maria sua Madre, salvamento de mina alma, crescimento de nimha honra, endereçamento de mina fazenda; porque as cousas que a Deos sao feitas, todas adiante hao de ir; e as que sem elle sao, todas hao de fenecer. E porém praza a Deos que haja boa gloria o mestre pedreiro, que fez este Castello.

24 Esta versión castellana de la inscripción se convirtió de momento en la “canónica” incluso en Portugal, así Fr. Pedro de Jesús María José dice que en la muralla de la villa de Alburquerque hay un letreiro que dice, y añade la versión ya comentada en castellano de Argote y de Brandao (de Jesús María José, 1754-1760: 217). Pero los investigadores lusos, en especial tras la reedición de la obra de Brás de Alburquerque (1774), retomaron la 
eran las únicas que existían sobre esta inscripción en el momento en que se hizo el acta notarial que estamos comentando (1747), siendo su imagen real la que ahora mostramos (figura $\mathrm{n}^{\circ} 8$ ).

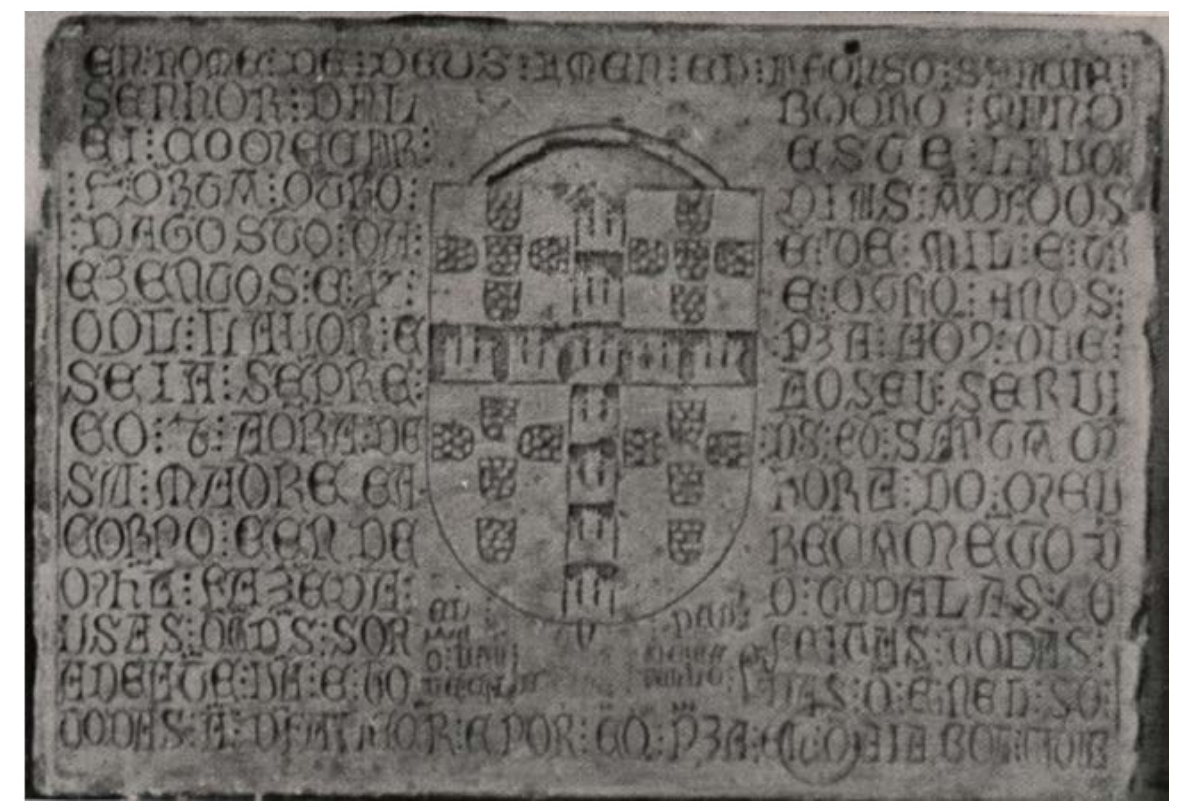

Figura 8. Inscripción de la muralla de la villa de Alburquerque, puerta de San Mateo o de la Villa (hoy en el Museo Arqueológico de Badajoz, foto artículos de Sousa).

\section{La Historiografía de la inscripción tras la realización del Acta notarial}

Desgraciadamente en Alburquerque no se hicieron, o al menos no se conservan, las famosas Relaciones Topográficas de Felipe II, que nos habrían informado de la situación de estas inscripciones en el último cuarto del siglo XVI. Tenemos que esperar al siglo XVIII para que se hiciera el acta notarial que estamos estudiando (1747) y que nunca salió a la luz, y a finales del mismo siglo para encontrar en el Manuscrito del Diccionario Geográfico de Tomás López un "Quaderno en que constan las antigüedades de la Villa de Alburquerque, Provincia de Extremadura. Sujetos que la poseyeron e ilustraron, con otras memorables noticias sacadas del Archivo de dicha villa y de otros antiquísimos Epitafios que se hallan en piedra en lengua gótica. Por Don Pedro Salgado Durán, Abogado de los Reales Consejos y Capitán de Milicias Urbanas de dicha Villa. Año de 1793” (Barrientos Alfageme,

lectura de éste como referencia para sus obras (Bezerra, 1785-1791: 407) y (Pinho Leal, 1873-1890: 142) que cuando habla de la Casa dos Bicos, y de la familia de su propietario, Brás de Alburquerque, vuelve a copiar el texto de esta inscripción que da el autor portugués. 
1991), que realizó la obra a la avanzada edad de 83 años ${ }^{25}$. Cuando trata de la historia de la villa y sus señores, cita la obra de Argote de Molina, y dice que Alfonso Sánchez fue el que reedificó el Castillo y reparó las Murallas, "cuya obra se proseguía en el mes de agosto de 1276, como consta en la inscripción que está en piedra de letra gótica sobre la puerta de la villa”. En principio podríamos pensar que el autor, que conocía y había citado el libro de Argote de Molina, se limitaría a copiar los datos de la inscripción dados por éste, pero sin embargo hace una lectura con algunas ligeras variantes, tanto ortográficas como de texto, aunque manteniendo siempre la lectura en castellano, primero la describe someramente: "Inscripción que está en piedra de letra gótica sobre la puerta de la villa”, y luego añade su lectura: "En el nombre de Dios sea todo Amen. Yo D. ${ }^{n}$ Sanchez señor de este Castillo de Alboquerque acabé esta labor à los quatro días de Agosto hera de 1314, lo qual sea para serbicio de Dios he de Santa Maria su Madre, é salvamiento de mi Anima, he crecimiento de mi honra he enderezamiento de mi facienda, por que las cosas que a Dios son fechas todas adelante ande hir, e las que sin el, todas ande fenecer he por ende plazeria à Dios que hay buena Gloria el Maestro Cantero que hizo este Castillo"26.

Esta lápida estuvo en su lugar original hasta los inicios de la época de la Restauración, y así lo recoge Pascual Madoz (1846: 349-350), que al hablar de los señores de la villa cita a Alfonso Sánchez, diciendo que tenía el señorío de la ciudad por su esposa, que reparó sus murallas y edificó el castillo, “según consta en una inscripción colocada sobre la puerta que llaman de la villa, lo que ha sido tomado como su fundación por algunos”, y a continuación da el texto, de nuevo en su versión castellana, tal y como aparece en la obra de Tomás López, que ya hemos visto es la lectura aportada por Pedro Salgado Durán. Tras los conflictivos años del Sexenio Revolucionario la lápida que comentamos, y la del escudo cuadrangular con inscripción (ver fig. 4a), pasaron en abril de 1876 a estar incrustadas en una pared de una de las habitaciones que ocupaba la Secretaría del Ayuntamiento. Esto se hizo por orden de la Corporación municipal, que nombró para verificar su traslado a la nueva ubicación al alcalde, don Pedro Oliveros Corón, al primer teniente de Alcalde, don Sabas Mariano Bejarano, y al secretario del Ayuntamiento, don Salustiano Duarte Soto. Posteriormente pasarían a formar parte del pequeño Museo o Colección que don Aurelio Cabrera Gallardo, un importante erudito autor de diversos trabajos sobre la villa, reunió en el castillo de Alburquerque, desde donde se llevó al Museo Arqueológico Provincial por gestiones del conocido historiador y correspondiente de la Real Academia de la Historia don Lino Duarte Insúa y del Apoderado de Defensa del Patrimonio

25 Como dice al inicio de su disertación, que firma en Alburquerque el 6 de abril de 1793, hace este trabajo “en cumplimiento de el Informe que el Cavallero Don Thomás López, agregado a la Secretaría de Estado, solicita se les dé por los Sres. Alcalde Mayor y regimiento en asumpto del Mapa conducente a la fundación y demás asumptos antiguos que ilustren este pueblo con arreglo a el Interrogatorio impreso a que soy encargado”, añadiendo que contará lo que recuerde, dada su edad, y por los veinte años que ocupó el cargo de regidor perpetuo de la villa, hasta que por sus ocupaciones renunció y fue entonces nombrado comisionado en el reconocimiento de su Archivo (Barrientos Alfageme, 1991).

26 Lectura de Pedro Salgado Durán (1793: 5). 
Artístico Nacional don Jesús Cánovas Pesini, en diciembre de 1943 (Duarte Insúa, 1929: 68) y (Delgado Serrano, 1950: 10-11) ${ }^{27}$.

Esta inscripción y la que rodea al escudo cuadrado de Alfonso Sánchez, serán copiadas en los Apuntes sobre la fundación e historia de Alburquerque, escritos por don Juan Duarte, e insertos en el folleto titulado La vida en Alburquerque. Noticia de lo que fue y compendio de lo que es. $1^{\circ}$ de enero de 1901, Badajoz (p.11), según nos dice José Ramón Mélida (1926) ${ }^{28}$. En el manuscrito de Mélida, que conservamos ${ }^{29}$, y en la posterior publicación, aparecen de nuevo estas dos inscripciones, con entrada 2415: Lápida que estuvo la sobre puerta de la villa, antes llamada de San Mateo, que hoy se conserva en el Ayuntamiento; y 2416: Lápida que estuvo sobre la puerta de la villa, llamada de Alcántara y hoy se conserva en el

27 Por todo ello ya existen datos, escuetos, sobre su ingreso y aparece una fotografía de la misma en las Memorias de Museos Arqueológicos Provinciales (AA.VV., 1944).

28 Dice también que se hallan recogidas memorias históricas y noticias varias de la villa y su término en un libro manuscrito del archivo del señor Duque de Alburquerque titulado Descripción de la Villa de Alburquerque (Texto, Tomo II, pp. 143-144.) , desgraciadamente no hemos podido encontrar el original de este manuscrito, pese a la ayuda de los responsables del archivo ducal sito en el castillo de Cuéllar, pero en la Biblioteca de la Real Academia de la Historia (signatura 11/8540) existe un texto mecanografiado por Aureliano Cabrera Gallardo, que firma en Toledo en 1933, y que titula Para la Historia de la noble villa de Alburquerque, añadiendo que es "copia del original manuscrito que existe en el Archivo del Excelentísimo Señor Duque de Alburquerque” y se encabeza en su primera página como "Descripción de la villa de Alburquerque”, el mismo título que da Mélida al manuscrito que vio en el Archivo Ducal, por lo cual creemos que esta copia realizada por el Sr. Gallardo está realizada sobre el original que vio Mélida. Este documento es muy interesante, está realizado en forma de cuestionario y responde exactamente a las preguntas del interrogatorio que diseñó Tomás López para la realización de su diccionario, por tanto este manuscrito debió ser contemporáneo y complementario a la obra ya citada de Pedro Salgado Durán, y por lo que parece, y él mismo dice, pudo ser también el encargado de recabar la información y redactar las respuestas al cuestionario, En cualquier caso, al hablar de la historia de la villa, y en concreto de Theresa de Meneses, casada con Alonso Sánchez, dice que éste fue el encargado de reedificar el castillo y reparar las murallas, como consta en la inscripción "que está en piedra de alabastro, Olior, que llaman en esta provincia, de letra gótica, que se halla fixada sobre la puerta principal de las Murallas y entrada para dentro de la Villa”, y a continuación pone el texto de la misma, en este caso la traducción castellana (pp.22-23), añadiendo que "en medio de la piedra e inscripción referida está también un escudo de Armas...yguales escudos al interior se ben sobre los Arcos de las Puertas denominadas de Alcántara y Valencia, que son las otras dos, que para entrar en la Villa adentro, y subir al Castillo, se halla en el circuito que abraza la muralla que cubre y encierra dicha Villa y Castillo, cuyas piedras de alabastro en que se hallan gravados dichos Escudos, son quadrilongas, ambas tienen alrededor ay inscripción de letra gótica que por el transcurso de los tiempos se halla bastante consumida, y en lo que se percive, lo que dice la de Alcántara es asi”, y añade la lectura que ya conocemos, con la particularidad que lee claramente las letras colocadas en los castillos de la parte superior de la cruz (Senhor deste logar). Por último dice que en la Puerta de Valencia existe el mismo escudo con la inscripción: “Christus Vincit, Christus Regnat, Christus Imperat, Era millesima CCC quadrugesima III”. Mélida dice que esta lápida, a la que da el nº 2417 (1296: 145-146), permanece sobre la puerta de la villa, llamada de Valencia, siendo un Tablero rectangular de alabastro en el que se ven esculpidos los mencionados blasones y la siguiente inscripción latina: Christus vincit, Christus regnat, Christus imperat. ERA M • CCC • IIII e IIII. Por su parte, Barroca, que le da el n ${ }^{\circ}$ 530, (2000: 14081409), dice que es ilegible, aunque piensa que su texto debía ser muy similar al de la Puerta de Alcántara, y ofrece imagen de ambos escudos con inscripción de las puertas de Alcántara, hoy en la plaza del Castillo, y la de Valencia, $n^{\circ}$ CLX-A 1 y 2, sin hacer ninguna referencia a la obra de Mélida y el texto que éste nos ofrece). Más adelante el cuestionario pregunta sobre si hay inscripciones antiguas, respondiendo que sólo hay la ya especificada “que se halla encima de la Puerta principal de esta Villa”, y luego vuelve a copiar el texto, pero esta vez se va a dar la lectura portuguesa de la misma (Barrientos Alfageme, 1991: 42-43), lo cual puede indicarnos que el cuestionario fue al final respondido por varias personas.

29 Completo en Biblioteca CSIC (2020) http://biblioteca.cchs.csic.es/digitalizacion_tnt/index_interior_ badajoz.html [Consulta 23/03/2020]. 
Ayuntamiento (la imagen que da Mélida de esta inscripción es nuestra figura 4a), añadiendo que están escritas en caracteres monacales ${ }^{30}$.

Con posterioridad también se publicó nuestra inscripción en la obra de Lino Duarte Insúa, que proporciona imágenes de las dos inscripciones que estamos comentado y aporta unas lecturas bastante acertadas, diciendo que están escritas en letras góticas (Duarte Insúa, 1929: 67-68); y por fin una referencia a su ingreso en el Museo Arqueológico Provincial (AA.VV., 1944: 43), que añade también una fotografía de nuestra inscripción.

Y será a partir de este momento, cuando la lápida entre oficialmente en las colecciones del Museo Arqueológico de Badajoz, cuando empiecen a realizarse estudios en profundidad sobre esta inscripción, que abordarán los varios problemas que existen en ella, mientras que en el lugar original donde estuvo hasta 1876 se ha colocado una réplica de la misma ${ }^{31}$.

\section{Ediciones recientes y estudio de los problemas de lectura: La fecha}

Tras su accidentada vida y transmisión, en el siglo XX estas inscripciones fueron estudiadas con detalle por el portugués José María Cordeiro de Sousa (1946: 449$460)^{32}$, y muchos años después lo hará su compatriota Mario Jorge Barroca (2000: 1296-1313), ya desde una metodología propiamente epigráfica.

30 Las lecturas de Mélida son las siguientes, para nuestra inscripción: Em nome de Deos amen. Eu Afonso Sanches / Senhor d'Albooquerque mand/ei comengçar este lavor f(eria) quarta, quatro días andados / d’Agosto, da era de mil a tr/ezentos e X e quatro anos / qual lavor e plazera a Deus que / seia sempre an seu servi/ço et a honra de Deus e de Santa María / sa Madre, ca honra do meu corpo e endereçamento da / minha fazenda, que todas las co/sas que a Deus son feitas todas / adelante van e todas (a sua) g(Loria) en el son / todas a Deus alecr e por eo praza a El que aia boa cima. Añadiendo que en caracteres más pequeños por bajo del escudo se lee: Eu mestre pedre/ro U sgr. De es/te castiello. En cuanto a la otra inscripción, la cuadrada que estuvo sobre la puerta de Alcántara, ofrece la siguiente lectura: $+E \cdot M \cdot I I I \cdot X \cdot I I I I$. Anos $\cdot$ IIII día/s d'agosto foi começado / este castello dallbo/querque de don Afonso Sanchez. Ahora bien Mélida no lee las letras que aparecen en la base de los tres castillos que forman la parte superior del brazo vertical de la cruz central, que añaden la frase: "Senhor deste logar", algo que sí leyó el autor de La Descripción de la Villa de Alburquerque (1793-1795) (que como ya hemos dicho conocemos por el texto mecanografiado en 1933 realizado por Aureliano Cabrera Gallardo) y Lino Duarte Insúa que dice que la puerta de Alcántara, sobre la que estaba esta inscripción estuvo en la llamada Plazoleta del Pozo de Alcántara, "fue tapiada para que un particular pudiera construir una casa con buen corral, cuya fachada da a la carretera” (Duarte Insúa, 1929: 67).

31 Museo Arqueológico de Badajoz (2020) http://museoarqueologicobadajoz.juntaex.es/web/ view/portal/ index/standardPage.php?id=112 [Consulta: 02/03/2020], que no nos ofrece transcripción, sino una foto de la lápida en el museo, otra del lugar original donde estaba y una posible traducción: "En el nombre de Dios, Amén. Yo Alfonso Sánchez, señor de Alburquerque, mandé comenzar esta obra la feria cuarta, transcurridos cuatro días de Agosto (del año) de la Era de Mil trescientos y cuarenta y cuatro (= jueves, 4 de Agosto de 1306 d.J.C.). Dios quiera que esta obra esté siempre a su servicio y para honra de Dios y de Santa María su madre, y para honra de mi cuerpo y beneficio de mi hacienda. Pues todas las cosas que con Dios son hechas, todas van adelante, y todas las que lo son sin Él deben perecer. Y por tanto que Él quiera que (esta obra) llegue a buen término. (Bajo el escudo). Yo, Pedro Vicente, maestre de este castillo lo hice”. Y añade la bibliografía existente sobre la misma con enlace a los textos completos.

32 Además de este artículo, Sousa escribió otros sobre los problemas de esta inscripción y las relacionadas con ellas en Alburquerque, que es necesario conocer (Sousa, 1945: 245-249), (Sousa, 1947: 153-164) y (Sousa, 1953: 261-282). Los datos y transcripciones aportadas en las obras de Sousa son el modelo para la publicación de una transcripción de estas inscripciones en el trabajo de Asunción Delgado Serrano (1950: 10-11), aunque no acepta todas sus lecturas y mantiene algunas de Mélida. 
Sus estudios son muy interesantes y van depurando las lecturas portuguesas realizadas desde época de Brás de Alburquerque hasta Mélida, aportando las oportunas correcciones y variantes del texto, aunque al menos la última palabra de la inscripción y el nombre del maestro cantero siguen generando algunas dudas, como indica el propio Barroca, que tampoco nos da el texto completo de la inscripción, como indicamos a continuación (Barroca, 2000). En los siguientes apartados analizaremos la lectura proporcionada por Barroca y resumiremos los problemas de interpretación de la misma, tratando de dar respuesta a estas cuestiones.

(A)

EN $\vdots$ NOME $\vdots$ DE $\vdots$ DEUS $\vdots$ AMEN $\vdots$ EU $\vdots$ AFONSO $\vdots$ SANCH(e)Z $\vdots /$

SENHOR $\vdots$ DALBOQ(ue)RQ(ue) $\vdots$ MAND / EI $\vdots$ COMECAR $\vdots$ ESTE $\vdots$

LAVOR / : F(eri)a $\vdots$ Q(ua)RTA $\vdots$ Q(ua)TRO $\vdots$ DIAS $\vdots$ AnDADOS /

DAGOSTO $\vdots$ DA $\vdots$ Era $\vdots$ DE $\vdots$ MIL $\vdots$ E $\vdots$ TR / EZENTOS $\vdots$ E $\vdots$ X' $\vdots$ E $\vdots$

Q(ua)TRO $\vdots$ ANOS $\vdots /$ O Q(ual)L $\vdots$ LAVOR $\vdots$ E $\vdots$ PraZA $\vdots$ A D(e)us $\vdots$ QUE

!/ SEIA $\vdots$ SEmPRE $\vdots$ AO SEU $\vdots$ SERVI / CO $\vdots$ e $\vdots$ A (h)OnRA $\vdots$ DE $\vdots$

DeuS $\vdots$ E De : SANTA Maria / SA $\vdots$ MADRE E A HOnRA $\vdots$ DO $\vdots$ MEU

/ CORPO $\vdots$ E ENDE / REnCAMEnTO De / MinHA ! FAZEnDA $\vdots$ Que :

TODALAS $\vdots$ CO / USAS : Que Com DeuS $:$ SON FEITAS $:$ TODAS $\vdots /$

ADEAnTE $\vdots$ VAm $\vdots$ E $\vdots$ TODAS $\vdots$ Que $\vdots$ Em $\vdots$ NEL $\vdots$ SOm / TODAS $\vdots$

AM $:$ De $\vdots$ FALECeR $:$ E POR $:$ Em Quem $:$ PraZA $\vdots$ EL $\vdots$ Que $\vdots$ AIA

BOA : CIMA (?)

(B)

EU $\vdots$ PED / rO $\vdots$ VicentE (?) $\vdots$ MestrE $\vdots$ DE $\vdots$ ES / TE $\vdots$ CAS TELLO

Antes de adentrarnos en la problemática en torno a la fecha de esta inscripción vamos a analizar la inscripción comentada anteriormente, la que se hizo alrededor del escudo del señor de la población, y que hoy se encuentra en la plaza de armas del Castillo, que en origen estuvo en la Puerta de Alcántara, y cuyo diseño es muy similar a la que se encuentra sobre la Puerta de Valencia, y que hoy en día es ilegible (Barroca, 2000: 1404). La lectura que nos da Barroca es la siguiente:

\section{$+\vdots$ Era $\vdots$ M $\vdots$ IIIc $\vdots \mathrm{X}^{\mathrm{a}} \vdots$ IIII $^{\mathrm{a}} \vdots$ ANOS $\vdots \mathrm{VII}^{\circ} \vdots$ DIA / S $\vdots$ De $\vdots$ AGOSTO $\vdots$ \\ FOI $\vdots$ COMECADO $\vdots$ / ESTE $\vdots$ CASTELLO $\vdots$ DALBO / Q(u)ERQ(u)E \\ De $\vdots$ DON AFONSO : SAnCHeZ / SENHor / DESTE / LOGAr}

El gran problema es decidir si está datada por la Era, que hubiera sido lo normal tanto en Portugal como en Castilla en esos años, o bien por el Año del Señor, sólo utilizado de forma generalizada por los eclesiásticos de ambos reinos en estos momentos. La solución parece sencilla por el contexto, ya que por los datos históricos que conocemos de su protagonista es imposible que se hiciera en el año 1276 (1314-38), siendo el motivo principal que Alfonso Sánchez ni siquiera había nacido, por tanto la fecha del inicio de la reconstrucción del castillo de la villa fue agosto de 1314, momento en que Alfonso Sánchez ya era señor de la totalidad de la 
villa (1308) y ocupaba el importantísimo puesto de mayordomo mayor del rey (desde 1312).

Sobre la posesión de esta estratégica villa hay que decir que sabemos que fue entregada por el rey Sancho I de Portugal (junto con 7000 morabetinos de oro) a una de sus hijas naturales, Teresa Sánchez, que fue la segunda esposa de un importante noble castellano, Alfonso Téllez de Meneses, señor de Meneses, que participó en la batalla de las Navas de Tolosa, con la condición de que debía conquistar y poblar esta villa, lo cual hizo unos años después, consolidando la presencia cristiana en la zona construyendo un importante castillo. De su primer matrimonio con Elvira Rodríguez descienden los señores de Meneses, su hijo Alfonso Téllez, padre de Mayor Alfonso de Meneses, que casó con el Infante Alfonso de Molina (hermano menor del rey Fernando III), siendo padres de Alfonso Téllez de Molina (1262-1314) señor de Meneses y de otros lugares, entre ellos la mitad del señorío de Alburquerque. Del segundo matrimonio de Alfonso Téllez de Meneses con la portuguesa Teresa Sánchez nace Juan Alfonso Téllez de Meneses (João Afonso Telo de Meneses), señor de la mitad de Alburquerque, alférez mayor del rey Alfonso III de Portugal, rico hombre en Castilla, donde Alfonso X le hizo Pertigueiro mayor de Santiago de Compostela, que fue padre de Rodrigo Anes de Meneses, casado con Teresa Martins de Soverosa, siendo padres de otro Juan Alfonso Téllez de Meneses (m.1304), que sería primer Conde de Barcelos (1298) en Portugal y ricohombre de Castilla, fue mayordomo mayor del rey Dinis de Portugal y casó con Teresa Sánchez, hija bastarda del rey Sancho IV de Castilla, siendo padres de Teresa Martins (de Meneses o de Telo), señora de la mitad de Alburquerque, que casó con Alfonso Sánchez, hijo bastardo del rey Dinis, fundando ambos el monasterio de Vila do Conde (1318), siendo este Alfonso Sánchez el protagonista de la inscripción de la muralla de la villa de Alburquerque.

Sabemos que don Alfonso nació en la década de 1280, probablemente en la segunda mitad, siendo muy querido por su padre, que le entregó numerosas donaciones y concertó su matrimonio con Teresa Martins, hija del poderoso Conde de Barcelos y heredera del señorío de Alburquerque, que tuvo lugar entre mediados de 1304 y principios de 1306. En este intervalo el rey lo legitimó por carta de 8 de mayo de 1304 y le hizo nuevas donaciones territoriales, además de conseguir hacerse con la totalidad del señorío de Alburquerque tras un intercambio con su pariente Alfonso Téllez de Molina en $1308^{33}$. Fue siempre un gran apoyo de su padre, de quien fue mayordomo mayor (1312-1323) ${ }^{34}$ y había tomado posesión del castillo y señorío de Alburquerque a la muerte de su suegro (1304), o más probablemente tras la boda con su hija y heredera, realizando desde entonces numerosas obras en él y en

33 El cambio fue confirmado el 25 de mayo de 1308 por el rey Dinis, pasando la villa de San Felices dos Galegos, que el rey había dado años atrás a su hijo (1304) a poder de Alfonso Téllez de Molina, a cambio de la "meyadade do castelo da vila d'Alboquerque, e por quanto hy auya o dito don Affonsso" (Sousa, 1946: 457-458) donde se copia el texto de la confirmación real del intercambio de propiedades. Además, Alfonso Sánchez debió entregar 60.000 dineros blancos a Alfonso Téllez de Molina para cerrar la operación (que el rey Dinis pagó en nombre de su hijo).

34 Sucediendo en este cargo a su suegro, el Conde de Barcelos, muerto en 1304, ya que el rey Dinis dejó vacante este importante puesto cortesano entre 1304 y 1312, para luego entregarlo a su muy leal hijo, el señor de Alburquerque, al que también nombró como uno de los dos ejecutores de su testamento (1322). 
la villa, con el fin de mejorar sus fortificaciones y defenderse de la enemistad manifiesta que le tenía su medio hermano, el futuro rey Alfonso IV de Portugal, lo que le obligó a retirarse a la corte de Castilla en $1324^{35}$, junto a su sobrino Alfonso XI, para luego morir a mediados de 1328, en el cerco de Escalona, ayudando al rey en su intento de derrotar a su rebelde pariente Don Juan Manuel (Arbor Aldea, 2005: 315-330).

Pasemos ahora a la datación de la segunda inscripción, la de la Puerta de San Mateo, cuya fórmula cronológica es la siguiente, según Barroca:

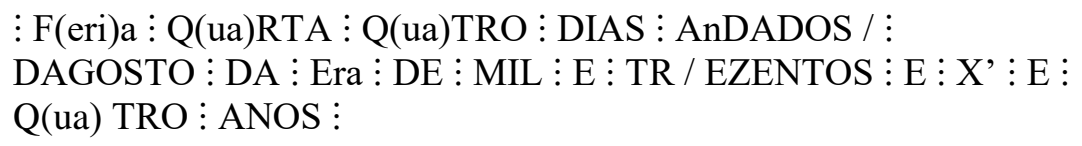

Hasta Barroca, la práctica totalidad de los autores que la estudiaron dieron por buena la lectura Era de 1314 años $^{36}$. Obviamente y con los mismos argumentos dados en la inscripción anterior aceptaron que la referencia cronológica no era la de la Era (Hispánica como se la denominaba en Castilla, o de César, nombre que se le daba en Portugal) usada en esos años de forma oficial por la administración castellana y portuguesa, sino del Año del Señor, y en especial Sousa la relacionó con la inscripción anterior, datada también en 1314, pensando que ambas se hicieron en un mismo momento cronológico, lo cual podría parecer muy lógico.

Ahora bien, estos argumentos tienen al menos un grave problema, la referencia a la "Quarta feria" para referirse a los "Quatro días andados de agosto". En 1314 el día 4 de agosto fue domingo, y no es fácilmente explicable esta disfunción, aunque Sousa lo intenta, de nuevo relacionando esta inscripción con la anterior, hablando de que el lapicida se confundió y al ver UII (7) en la comentada anteriormente, hizo una mala lectura por IIII y eso fue lo que puso en esta, cuatro, siendo en realidad un siete lo que debería haber puesto, y así se soluciona el problema, ya que efectivamente el 7 de agosto de 1314 fue miércoles, cuarta feria (Sousa, 1946: 455456). Sousa no aceptó los argumentos de algunos paleógrafos que le escribieron para indicarle que la $\mathrm{X}$ que él interpretaba como diez era en realidad una $\mathrm{X}$ aspada que debía leerse como cuarenta, siendo por tanto la data 1344, lo que obligaba a desechar la interpretación del Año Señor, y volver a la de la Era Hispánica, siendo entonces el año de la inscripción de la Puerta de San Mateo el de 1306.

35 Este “exilio” parece ser que está relacionado con las condiciones que el Infante Heredero Alfonso obligó a su padre, el rey Dinis, a aceptar para conseguir la definitiva paz entre ambos (hubo entre los dos una verdadera guerra civil entre 1319 y 1324 que pareció acabaron la firma del acuerdo de mayo de 1322, aunque hubo nuevos enfrentamientos en las cortes celebradas en Lisboa en octubre de 1323, firmándose un nuevo pacto en febrero de 1324), lo cual no fue suficiente para el Príncipe, que tras subir al trono (1325) ordenó la confiscación de los bienes que su medio hermano tenía en Portugal, lo que provocó nuevas tensiones entre ambos, que llevaron a varios enfrentamientos armados, que no acabaron hasta que la reina viuda Isabel de Aragón (luego Santa Isabel), consiguió que ambos firmaran una paz duradera (1326).

36 Salvo el padre Carlos da Silva Tarouca que lee Era de 1344 (Tarouca, 1960: 181). 


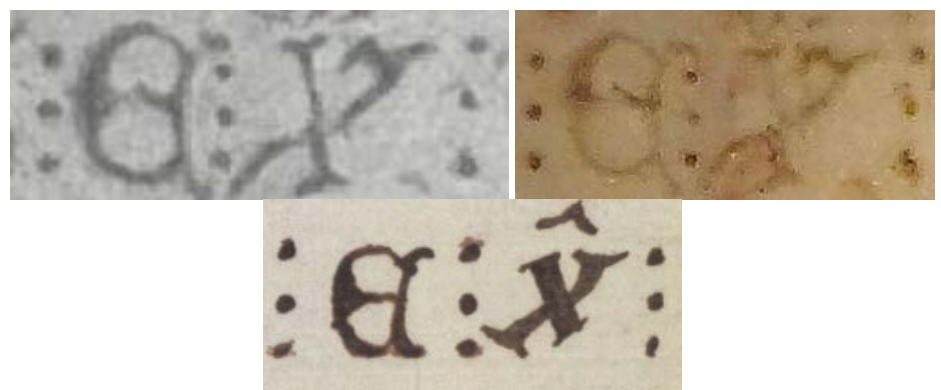

Figura 9. Fotos de detalle de la inscripción (Memorias 1944 y Museo 2019) y la del acta notarial (1747).

Barroca no tiene dudas de lectura y ve claramente la X aspada (XL), que él cree que utilizó el lapicida para mantener una correcta distribución del texto de la inscripción, quedando de esta forma los diversos datos cronológicos bien ordenados en torno al escudo, que ocupa el centro de la inscripción, y dejando todo el texto perfectamente encuadrado dentro del campo epigráfico, algo que no hubiera sido posible utilizando la expresión numérica "QUARENTA". Se trata, pues, de un recurso de diseño epigráfico empleado por el lapicida para lograr una ordinatio perfecta $^{37}$.

Esta lectura nos lleva por tanto al año de 1306, pero no nos soluciona el problema de la "cuarta feria", ya que el día 4 de agosto de ese año fue jueves (quinta feria). Barroca lo explica hablando de la especificidad del cómputo portugués, que toma el domingo como primer día de la semana, mientras los castellanos entienden que el domingo es el final de la semana, empezando ésta el lunes. Por tanto, si seguimos dicho cómputo castellano el jueves sería efectivamente la cuarta feria. Pasa luego a argumentos históricos. Sabemos que Alfonso Sánchez se convirtió en Señor de Alburquerque por su matrimonio con Teresa Martins, hija del conde de Barcelos, que en su testamento (5 de mayo de 1304) se lo deja en herencia a pesar de ser la segunda de sus hijas ${ }^{38}$, estando aún

37 El problema de aceptar o no la $\mathrm{X}$ aspada es complejo. Fue un recurso muy habitual en todo tipo de documentos escritos en letra visigoda y visigótica en diferentes soportes, pero luego fue desapareciendo de forma paulatina y no hemos encontrado su uso en inscripciones de letra gótica, por lo cual sigue siendo un tema de debate. Unos ven claramente este recurso, que además mostraría el buen conocimiento de las llamadas "letras antiguas” por parte de quien hizo la redacción y diseño final de la inscripción antes de pasarla al lapicida; otros sin embargo sólo ven un reforzamiento del remate de la letra y creen que no tenía sentido el uso de la $\mathrm{X}$ aspada en pleno siglo XIV.

38 Además, en ese testamento se habla de los dineros que estaban ya en Alburquerque para hacer construcciones en ella, por lo que vemos que las obras de fortificación ya estaban diseñadas y a la espera de comenzar a la muerte del conde de Barcelos, que ordenaba que fueran devueltos a Portugal y entregados al rey Dinis si no se hacían las obras antes comentadas. De esta forma el proyecto de remodelación de las defensas de la villa planeado por Barcelos sería retomado por su yerno, Alfonso Sánchez, con el apoyo de su padre, poco después de su matrimonio con la heredera del señorío, que por lo que estamos viendo debió realizarse poco antes de colocar la inscripción que estamos comentado. Obsérvese que el testamento del conde es de fecha 5 de mayo de 1304, y Alfonso Sánchez fue legitimado por su padre, el rey Dinis, por carta de 8 de mayo de 1304, lo cual podría indicar que el monarca ya tenía intención de casarle con la hija de Barcelos, cuyas estratégicas posesiones engrosarían el patrimonio de su hijo evitando así que pasaran a algún noble que pudiera serle desafecto. El testamento de encuentra transcrito (Sousa, 1947: 161-162). 
soltera; y don Alfonso aparece con este título señorial por primera vez en diplomas de 1307, pues bien la hipótesis es que el rey Dionisio debió decidir casar a su hijo favorito con esta rica heredera para asegurar su futuro, recordemos la fecha de la legitimación del bastardo (mayo de 1304), debiendo realizarse el enlace entre mediados de 1304 e inicios de 1306, y como afirmación de su nueva condición de Señor de Alburquerque (por matrimonio) pudo decidir hacer esta inscripción (4 de agosto de 1306) mostrando en el centro su escudo de armas de grandes proporciones, y su interés por la villa iniciando las obras de mejora de su sistema defensivo, que culminarían tras conseguir la totalidad del señorío de la villa (1308) con un nuevo programa de construcciones, que son las que aparecen detalladas en la inscripción de 1314 ya comentada y posiblemente en la ilegible de la Puerta de Valencia (Barroca, 2000: 1300-1307).

Para terminar con este tema, Barroca piensa que las inscripciones de 1314, y en concreto la que está descontextualizada y hoy situada en la plaza de armas del Castillo, pudo haber estado originalmente colocada en la Puerta de San Mateo, encima de la inscripción de 1306, ya que existe sobre ella una moldura rectangular, más alta que ancha, hoy vacía, que tiene la forma que adoptan las inscripciones de 1314, y podrían haber servido para reafirmar el dominio del Señor de Alburquerque sobre este lugar, en su momento de mayor poder, recordemos que en esos años era mayordomo mayor del Rey (Barroca, 2000: 1405).

Nos parece una teoría coherente, aunque si estudiamos atentamente la documentación, la inscripción de la plaza de armas del Castillo estuvo originalmente en la Puerta de Alcántara, por ello pienso que podría ser que existiera una tercera inscripción, hoy desparecida, de las mismas características en forma y diseño que las de las Puertas de Alcántara y de Valencia, que ocuparía el espacio vacío hoy existente en la Puerta de San Mateo, completando así el diseño iconográfico heráldico que mostraba las armas del Señor en su forma cuadrangular en las tres grandes puertas de la villa, la de Valencia (que se conserva dentro de una moldura), la de Alcántara (hoy en la plaza de armas del Castillo), y la de San Mateo (que tendría dos inscripciones, una de 1306 y otra probablemente de $1314)^{39}$.

39 Estas inscripciones y la heráldica propia de los primeros señores de esta villa pronto dejaron de ser representativa. Tras la muerte de Juan Alfonso de Alburquerque (1354), el hijo de Alfonso Sánchez, esta villa y muchas de sus otras posesiones terminarían pasando a la Corona en las turbulencias de la segunda mitad del siglo XIV, que la fue entregando a diferentes señores. Así Sancho Alonso, hijo bastardo de Alfonso XI y hermano de Enrique II fue nombrado por éste Conde de Alburquerque (1366) (además de ser señor de Haro, Briones, Belorado, Medellín, Tiedra, Montalbán, etc.) y tras su muerte (1374) todas sus posesiones pasaron a su hijo Fernando (que murió sin hijos en 1385), y luego a la hermana de éste, Leonor, conocida como la Rica Hembra por su gran herencia, por ello se la casó con su sobrino, el Infante Fernando de Antequera, y por ello se convirtió en reina consorte de Aragón (1412), cuando éste se convirtió en rey Fernando I tras el Compromiso de Caspe. La cuantiosa herencia castellana de este matrimonio se repartió entre sus hijos menores, los llamados Infantes de Aragón, recibiendo los condados de Alburquerque y Ledesma, y otras villas, el Infante Enrique, que fue además Maestre de la Orden de Santiago, y se enfrentó en numerosas ocasiones a su primo Juan II de Castilla, que le terminó confiscando sus bienes, entregando Alburquerque a su privado, don Alvaro de Luna (1432), que la une a su mayorazgo, siendo nombrado su hijo Juan Conde de Alburquerque (1447), pero tras su caída en desgracia y posterior ejecución, la villa vuelve a la Corona (1453). Unos poco años después Enrique IV la entregará a don Beltrán de la Cueva, que se convertirá en Duque de su nombre (1464), en compensación por ceder el Maestrazgo de Santiago al Infante Alfonso (fue también conde 
Creemos por tanto, que estas disfunciones cronológicas podrían, tal vez, ser explicadas por ser la persona encargada de entregar el texto definitivo de la inscripción en portugués al lapicida un castellanoparlante, algo lógico en la zona que estamos estudiando, y por ello el error en cuanto al uso de la feria, que un portugués nunca hubiera cometido, manteniendo sin problemas el uso de la Era, por entonces en vigor tanto en Castilla como en Portugal, y que debe primar para determinar la fecha exacta de la inscripción. Incluso este hecho podría explicar también otros problemas de interpretación en el texto concreto de la inscripción.

\section{Ediciones recientes y estudio de los problemas de lectura: La suscriptio del Maestre del Castillo}

Brás de Alburquerque habla del "mestre pedreiro" y Argote del maestro cantero, y todos los que posteriormente hablan de esta inscripción en los siglos XVII al XIX mantienen esta interpretación, sin identificar la $\mathrm{U}^{\mathrm{E}}$ que aparece antes de la abreviatura de Maestre $\left(\mathrm{M}^{\mathrm{E}}\right)$. Al empezar el siglo XX Mélida mantiene esta lectura (Eu mestre pedro/ro U sgr. De es/te castiello), y en su texto manuscrito (eliminado luego de la publicación), dice que "es de lamentar que la primera y más extensa inscripción no nos haya conservado el nombre del maestro pedrero que realizó tan importante obra de fortificación” (fol.119), aunque en su lectura de estas líneas deja algunas importantes dudas que no resuelve (en especial el sgr. que coloca tras la U).

La transcripción del acta notarial (1747) sigue esta línea entendiendo que aparece la palabra PEDRO con un signo de abreviación sobre la última letra interpretando que quisieron decir PEDR(eir)O, una lectura que ya daba Brás de Alburquerque. Será Sousa (1945) el primero en hablar de que el maestro de estas obras tenía por nombre Pedro Vicente, mientras que Asunción Delgado mezcla datos aportados por Mélida y Sousa para hablar de un Pedro Usagre, añadiendo que "esta pequeña inscripción algunos investigadores la dan como continuación de la grande y otros como completamente independiente (Delgado Serrano, 1950: 10). La redacción de la lápida admite ambas posibilidades”. Sousa se reafirma en su lectura (1953) y Barroca (2000) le sigue, aunque con dudas ${ }^{40}$.

de Ledesma, señor de Aranda, Roa, Molina, Atienza, Cuéllar, etc.). La villa no lo aceptó de buen grado, y hubo múltiples protestas, que incluso terminaron en un verdadero alzamiento armado, aunque al final la tuvo que aceptar, quedando desde entonces en manos de esta Casa Ducal. Como vemos poco interés habría en mantener en los tiempos posteriores los símbolos de los primeros señores de la villa, de claro origen portugués, como lo demostraban sus escudos, y a que a los habitantes de esta localidad no debían traerles buenos recuerdos, por haber sido atacada, sitiada e incluso ocupada varias veces por los portugueses (1395, guerra de Portugal de 1640, guerra de Sucesión, donde los anglo-portugueses ocuparán la villa en 1705, y no la abandonarán hasta 1716, cuando se firmaron las paces generales en Europa, la Gaceta de Madrid de 14 de enero de 1716 nos informa que los portugueses evacuaron la plaza y el castillo el 9 de enero, entrando las tropas del rey el mismo día, tomando posesión de las mismas). Parece claro que serían los emblemas de los nuevos señores de la villa los que deberían ocupar los lugares más señalados de la misma, recordando a sus habitantes de quienes dependían y las construcciones que se hacían en su nombre, ya fueron defensivas, piadosas, asistenciales o cualesquiera otras.

40 Lecturas de la suscriptio. Mélida (1926): Eu mestre pedre/ro U sgr. De es/te castiello Acta Notarial (1747): EU : $:$ PEDRŌ $: U^{E}: M^{E}$ : DE $\vdots$ ESTE $\vdots$ CASTELLO 


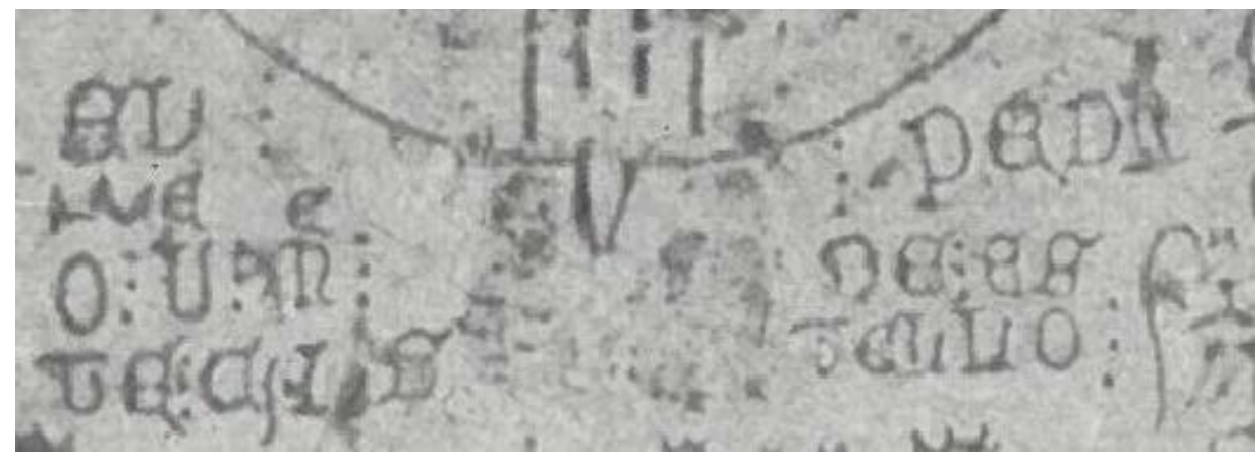

Figura 10. Detalle de la suscriptio ejecutada bajo el escudo.

Mientras todos los que hacían la lectura portuguesa y la traducción castellana siempre hacían referencia al maestro que fez - fizo/hizo este castillo, los que transcriben la inscripción no hacen referencia ninguna a la letra o palabra que en la inscripción pueda hacer referencia al verbo hacer, y sin embargo para nosotros parece clara su existencia, que no se ha puesto de manifiesto en ninguna de las transcripciones de esta inscripción. Si nos fijamos en la suscriptio, al finalizarla con los tres puntos, aparece junto a ella una $\mathrm{F}$ (con un signo de abreviatura en la parte superior derecha de la misma) fuera de la línea de escritura y de gran tamaño, con un módulo y factura similar a las grafías de la inscripción principal y significativamente superior a las de la suscriptio, casi dos veces y media el tamaño de sus últimas letras. Si bien, queda emplazada fuera del campo epigráfico de esta inscripción lo que, dada la perfecta distribución del texto que presenta, evidencia que no pertenece a esa inscripción.

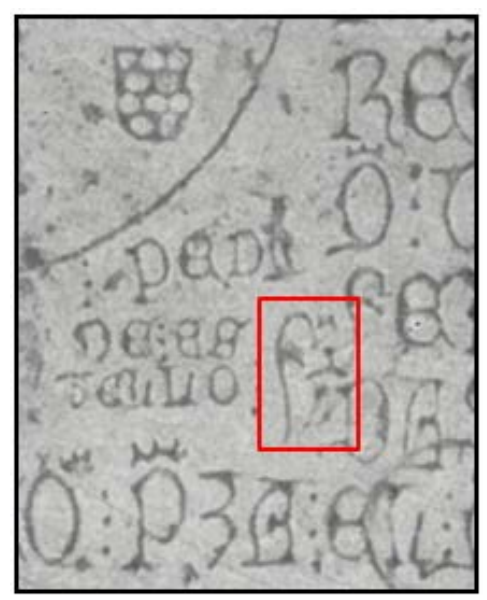

Figura 11. Detalle de la grafía F que actúa como fórmula notificativa en la suscriptio. 
Como hemos indicado, esta $\mathrm{F}$ no aparece en ninguna de las transcripciones realizadas de esta inscripción durante el siglo XX, aunque a nuestro entender sí debió ser "leída" por los anteriores editores de la inscripción que la interpretaban como una especie de "fiz", es decir un "lo hizo" refiriéndose al maestro de obras del castillo.

A nuestro modo de ver, esta fórmula roborativa debió ser añadida con posterioridad a la ejecución de la inscripción y el escudo, aprovechando un espacio vacío que quedaba tras la preparación del espejo epigráfico.

Es suficiente con un simple vistazo para presuponer la distribución armónica del texto sobre el soporte, empleando el escudo como el elemento central en torno al cual se organizó el texto. Sin duda, debió ser obra de un rogatario experimentado, quien se valió de la figura del rectángulo de proporcionalidad creciente para la organización armónica de la composición ${ }^{41}$, aunque debemos señalar que la superficie epigráfica tiene una anchura de apenas un centímetro mayor que la del rectángulo resultante de esta operación.

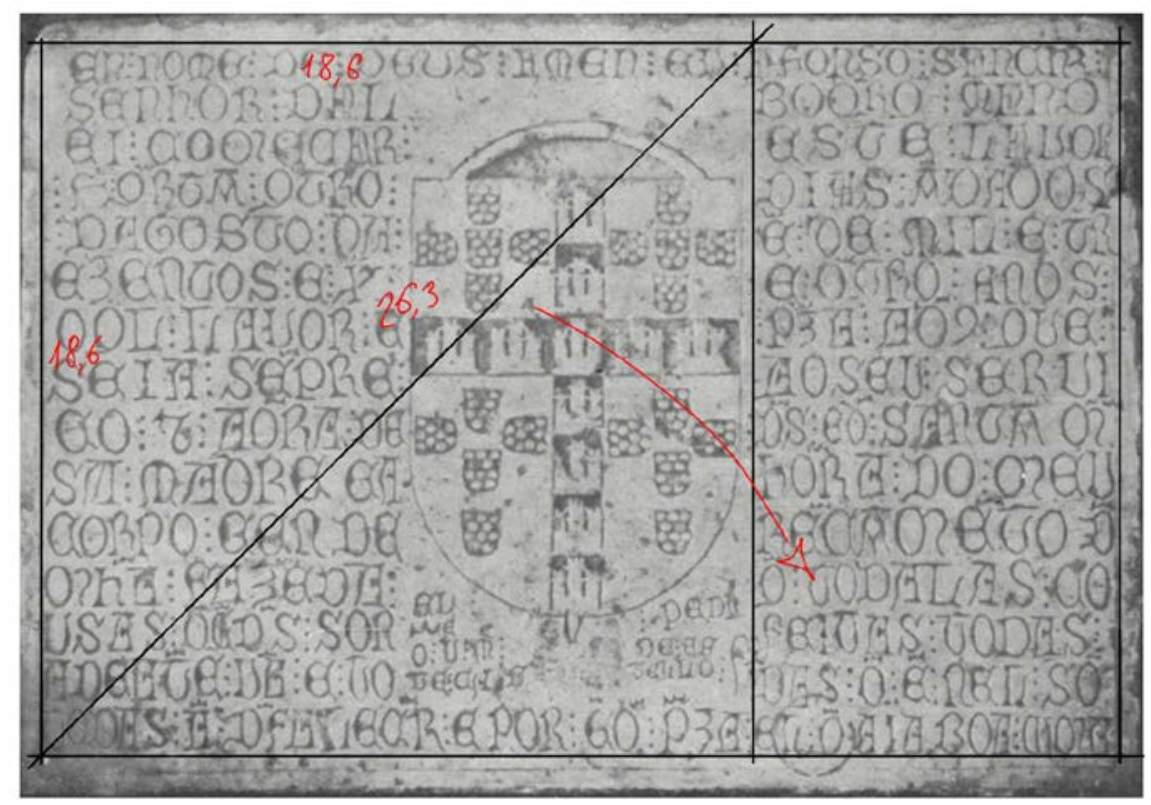

Figura 12. Reconstrucción del proceso de impaginatio de la inscripción para obtener la superficie del espejo epigráfico.

Una vez obtenida la superficie donde ejecutar el texto, se utilizó la forma rectangular vertical obtenida de la construcción del rectángulo (con una anchura de

41 El estudio de la denominada como impaginatio, término con el que se denomina al diseño del espacio epigráfico para la correcta distribución del texto sobre él, es una de las recientes aportaciones de la Epigrafía Medieval, obteniéndose interesantes resultados al respecto que nos permiten conocer con mayor profundidad el trabajo de los rogatarios en la génesis epigráfica (Martín López; García Lobo, 2012). 
9,2 cms.) delimitando el espacio epigráfico obtenido, a su vez, en tres secciones rectangulares, encajando el escudo heráldico en la central. Por último, y una vez construidas las líneas guía de los renglones, se centró el escudo con dos líneas de escritura una escrita y otra en blanco, por arriba y abajo, aunque con diferentes tamaños al ir aumentando ligeramente el tamaño de las líneas de escritura conforme baja el texto.

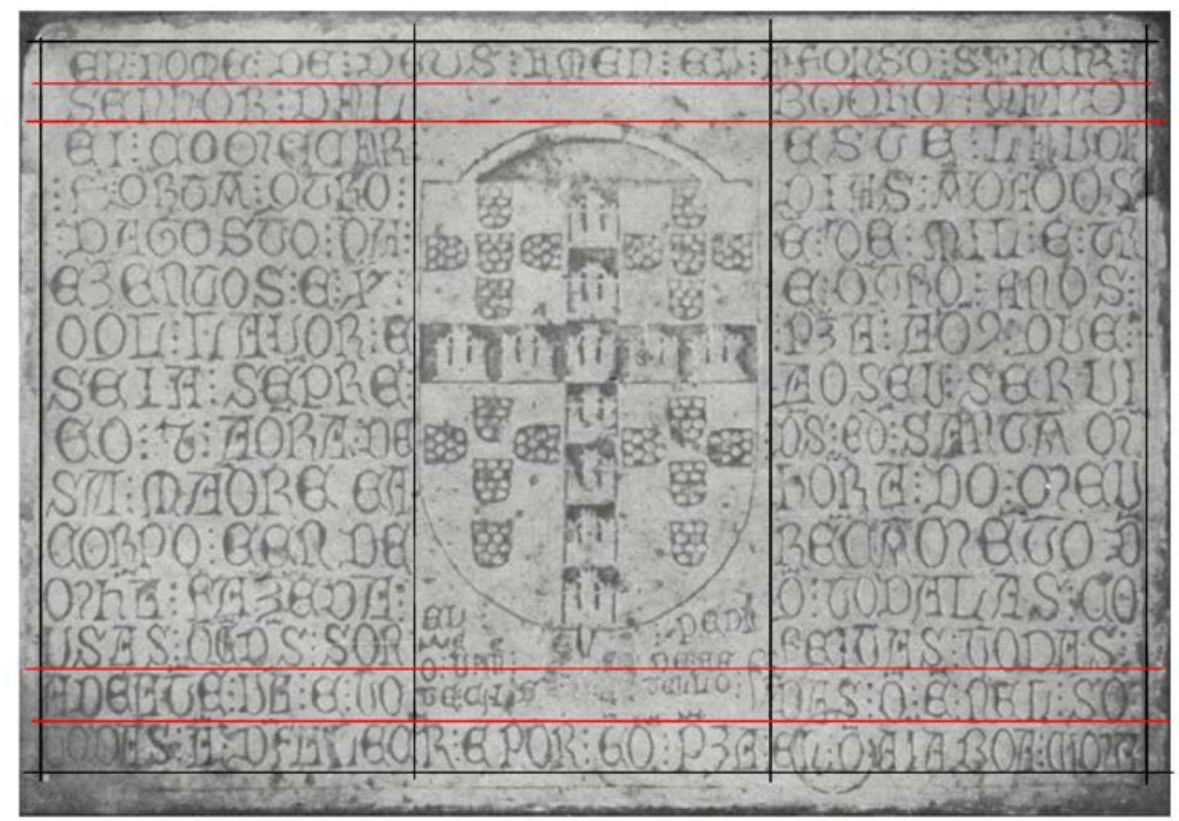

Figura 13. Reconstrucción del proceso de impaginatio de la inscripción en el momento que se fija el área para insertar el escudo de armas.

Todo ello nos invita a pensar que, aprovechando la existencia de un espacio libre dentro del espejo epigráfico con unas dimensiones suficientes, el rogatario decidió ejecutar la segunda inscripción, la suscriptio, que además presenta una ejecución más espontánea e irregular, con diferentes módulos en las grafías y, en definitiva, menos planificada que el resto de la composición.

Resulta complicado determinar el momento en el que se hizo esta segunda inscripción, aunque dada la similitud de sus elementos externos e internos con la principal intuimos que debió realizarse con cierta inmediatez a la finalización de la composición.

Con todo, la lectura sigue siendo para nosotros compleja y no nos termina de gustar ninguna de las realizadas, la abreviatura sobre la $\mathrm{O}$ inicial de la segunda línea pudiera avalar más la tradicional lectura de pedreiro que la de Pedro, con lo cual tal vez deberíamos leer: EU PEDR(eir)O V(icent)e M(estr)e DE ESTE CASTELLO F(iz), es decir con cierta literalidad, "Yo, el cantero Vicente, maestre 
de este castillo, lo hice" ${ }^{42}$, aunque creemos que se debe seguir investigando sobre este tema, siendo esta lectura la que aparece en el acta notarial de 1747 , salvo la $\mathrm{F}$ final, que como hemos indicado no aparece en ninguna transcripción posterior.

\begin{tabular}{|l|l|l|l|}
\hline \multicolumn{4}{|c|}{ Historiografía de la INSCRIPCION DE LA PUERTA DE SAN MATEO } \\
\hline Bras de Albuquerque & \multicolumn{1}{|c|}{$\begin{array}{c}\text { Lectura en } \\
\text { portugués }\end{array}$} & $\begin{array}{c}\text { Traducción } \\
\text { castellana }\end{array}$ & Transcripción \\
\hline Argote de Molina & & X (1588) & \\
\hline Brandao & & $\mathrm{X}(1672)$ & \\
\hline Acta Notarial & & & $\mathrm{X}(1754-1760)$ \\
\hline Jesus Maria Jose & & & \\
\hline Bezerra & $\mathrm{X}(1785-1791)$ & $\mathrm{X}(1793)$ & \\
\hline Pedro Salgado Durán & & $\mathrm{X}(1793-1795)$ & \\
\hline Descripción Villa & $\mathrm{X}(1793-1795)$ & $\mathrm{X}(1846)$ & \\
\hline Madoz & & & \\
\hline Leal & $\mathrm{X}(1873-1890)$ & & \\
\hline Duarte & $\mathrm{X}(1901)$ & & $\mathrm{X}(1946$ y 1953) \\
\hline Mélida & $\mathrm{X}(1926)$ & & $\mathrm{X}(2000)$ \\
\hline Duarte Insúa & $\mathrm{X}(1929)$ & & \\
\hline Sousa & & & \\
\hline Memorias MAP & & & \\
\hline Barroca & & & \\
\hline
\end{tabular}

Tabla 1. Tabla resumen de la historiografía de la inscripción.

\section{El Acta Notarial de 1747}

Después de todo lo comentado anteriormente y resumida la historiografía de la inscripción, procedemos con el análisis del acta notarial. Pero antes unas palabras sobre la situación de la Villa en estos momentos tomados del manuscrito copiado por Aureliano Cabrera Gallardo en 1933, que como ya hemos dicho fechamos en 1793, siendo coetánea de la obra de Pedro Salgado Durán que la complementa ${ }^{43}$.

42 Algunas de las grafías de esta segunda inscripción nos han presentado dificultades para su identificación, las cuales hemos podido resolver a partir de criterios paleográficos y lingüísticos. El caso más destacable es el de la U en la primera palabra, cuyo ductus podría invitarnos a identificarla con una L, o incluso con una T, si la comparamos con otros ejemplos del mismo monumento. Si bien, creemos más correcto atribuirle el valor U por dos motivos: en primer lugar, el parecido existente en el trazo de U y L y la variedad de formas que este presenta en la inscripción, desarrollando más o menos el segundo trazo, y en segundo lugar, la lengua en que se redactó la inscripción, el portugués, nos hace inclinarnos por la lectura del pronombre personal eu, del mismo modo que aparece en la inscripción principal en la formula intitulativa.

43 Aunque debemos citar también el Interrogatorio de la Real Audiencia, Partido de Badajoz (1994: 115-141), llevado a cabo en abril de 1791. Recordemos que aunque la idea original fue de Carlos III (1776), la Real Audiencia de Extremadura no se creó oficialmente hasta que Carlos IV otorgó la preceptiva Pragmática Sanción (30 de mayo de 1790), estableciéndose en Cáceres en el antiguo Hospital de la Piedad, inaugurándose oficialmente el 27 de abril de 1791, y por ello unos meses antes (enero) y en cumplimiento de una Real Orden del Supremo Consejo de Castilla, el Regente de la Audiencia dispuso que cada uno de los 8 ministros que la componían realizara una visita a cada uno de los partidos de su jurisdicción, que debían completar un interrogatorio concreto de 57 preguntas, siendo los encargados de responder los justicias, párrocos, 
Este texto nos dice que "El Govierno Político Gubernativo y económico de la Villa, desde 1740, se compone del Corregidor, que es de letras, quien exerce la Real jurisdicción ordinaria, seis Regidores, uno de ellos con título de Teniente y un Procurador Síndico General con boto, y quatro escribanos numerarios, todos los quales se nombran por el Excmo. Sr. Duque de Alburquerque, despachándoles para ello el correspondiente título por el tiempo de su voluntad" (Cabrera Gallardo, 1933: $37-38)^{44}$, en lo militar dice que la villa, al ser plaza de armas, tiene "una

Ayuntamientos y personas particulares de los distintos pueblos. En nuestro caso será el alcalde mayor, Francisco Sánchez Santiago, el responsable de responder esta encuesta, donde se dice que: "Es villa y plaza de armas, no es caveza de Partido, es del de la ciudad de Badajoz, que dista 6 leguas a su norte, todos los pueblos confinantes exepto los nominados de Portugal son del territorio de la Audiencia y antes lo eran del de la Chancillería de Granada. Es villa de señorío correspondiente a el Excelentísimo Señor Duque de su nombre, cuia jurisdiccion ordinario es suia unicamente aunque poseé algunas otras heredades en concepto de dominio particular, el de alcalde mayor que es quien exerce dicha Real Jurisdiccion y en sus ausencias y enfermedades uno de los regidores, mediante titulo que a uno y a otro se despacha. Nombra seis regidores y un procurador sindico general, que lo suelen ser vitalicios; los dos diputados de abastos y procurador personero los nombra el comun con arreglo a ordenes. Tiene dicho alcalde maior la subdelegacion de las causas de denuncias de vienes mostrencos, vacantes y abintestatos; el salario que le da anualmente su excelencia son doscientos ducados y de propios por presidente de la junta tiene doscientos reales; las terceras partes de denuncias de campo, montes, multas prosezales y vervales, le valen anualmente quatro mil treszientos reales vellon y las obenciones y derechos del juzgado como mil reales que unidas a dichas partidas componen el total de siete mil setecientos reales. Los regidores tiene cada uno en propios por via de salario cien reales anuales y los dos que son de la junta de propios cien reales mas, turnando al intento; hay tres abogados; quatro procuradores, de los que uno de ellos es promotor fiscal y se nombran por su excelencia quatro escrivanos reales y numerarios, uno de ellos exerce la de ayuntamiento y otro la de guerra, son suficientes para las causas que ocurran, no tienen salario fixo y si unicamente los derechos que devengan por su travajo, exepto el de ayuntamiento que tiene de propios seiscientos sesenta reales. Hay dos ministros para el juzgado, tiene cada uno de salario anual librado en propios ciento noventa y ocho reales, los derechos de carcelaje y citaciones; hay cinco guardas de campo y monte vajo de igual nombramiento y anual salario de trecientos treinta reales de propios, con mas de las terceras partes de las denuncias; assi mismo hay otros tres supernumerarios sin salario, con solo el que devengan por las terceras partes de denuncias, que ascenderán a cosa de quatro mil quinientos reales, poco mas o menos; un pregonero con 330 reales de propios. El aranzel que observa el juzgado es de la Real Chancilleria. El destino que se hadado a los protocolos y papeles de los oficios de escrivanos reales y numerarios ha sido mui vario y sin precaucion ni resguardo, a causa de haverse ajudicado los papeles a los herederos o heredero del escrivano difunto, por lo que se hallan dispersos, sin metodo ni colocacion alguno en poder de los particulares que los han adquirido, ya por titulo de compra o herencia, por lo que seria util se recojiesen y colocasen con separacion de escribanias en un archivo publico y vajo tres llaves que corriesen a cargo para la custodia y seguridad de instrumentos del alcalde mayor, regidor decano y escrivano de ayuntamiento, segun está el de los de villa. Hay para el govierno de esta villa dos ordenanzas, unas del año de 1591 que se hallan solo aprobadas por su excelencia y otras del año de 1615 con aprovacion del Consejo. Esta villa como plaza de armas tiene una planta maior compuesta de governador, theniente de rey, sargento maior, ayudante y capitan de llaves; hay agregados a ella tres capitanes y un theniente con una compañia de ymbalidos compuesta de capitan, theniente, alferes, quatro sargentos, dos de compañia y dos agregados, y diez hombres; assi mismo un destacamento de artilleria compuesto de un subtheniente, un cabo y doze soldados. Hay ocho compañias de milicias urbanas compuesta cada una de capitan, theniente y alferes, quatro sargentos y ocho cabos que son los que gozan de fuero, a causa de que los soldados solo se alistan quando Su Majestad (que Dios guarde) lo manda. Hay dos thenientes de milicias provinciales, el uno de las de Badaxoz y el otro de las de Truxillo" (1994: 115-141).

44 Para más datos sobre este tema se pueden ver las referencias que nos da Pedro Salgado Durán, donde dice que por gracia y cesión del Rey Felipe V (1740), el Duque, extinguidos los antiguos oficios anuales, podría nombrar (y lo mismo sus sucesores), un alcalde mayor de letras, un teniente que ejerciera la jurisdicción del anterior en ausencias y enfermedades, seis regidores, un procurador síndico general, un mayordomo de Concejo y los Escrivanos, siendo de su cuenta la paga del salario del alcalde mayor y que los pudiera quitar y remover con causa o sin ella. Los primeros nombramientos de esta nueva forma de gobierno se dieron el 8 de septiembre de 1740, siendo uno de los primeros seis regidores nombrados el citado Pedro Salgado Durán (Cabrera Gallardo, 1933). 
plana mayor compuesta de Governador (que tiene que exercer la jurisdicción militar nombrado por el Rey), Teniente de Rey, Sargento Mayor, Ayudante y un Capitán de Llaves. Hay agregación de un Mariscal de Campo, tres capitanes, un teniente con una Compañía de inválidos, compuesta de capitán, teniente y subteniente, quatro sargentos, dos de compañía y dos agregados. Hay un guarda de almacén y un destacamento de artillería, compuesto de un Teniente, Sargento y doze soldados. Hay también ocho compañías de Milicias Urbanas compuesta cada una de Capitán, teniente y subteniente, quatro Sargentos, y ocho Cavos, que son los que gozan únicamente de fuero, con arreglo a lo prevenido por Real Orden de 19 de septiembre de $1767 . .$. También hay dos tenientes de Milicias provinciales, el uno de las de Badajoz y el otro de las de Trujillo” (Cabrera Gallardo, 1933: 38-39).

Sabiendo la organización administrativa de la villa a mediados del siglo XVIII y la realización del acta notarial por Manuel Diaz Luzio “escribano del Rey nuestro señor publico y de los de numero de esta villa de Albuquerque... por mi y con asistensia del señor corregidor desta villa”, debemos preguntarnos quién solicitó este acta y porqué, ya que el texto no nos da ninguna referencia sobre estos asuntos. Del mismo modo hay que decir que un acta notarial siempre tenía un coste económico, el uso del papel sellado y los honorarios del escribano, que en este caso podrían ser más elevados si hubo que hacer unos extras, nos referimos a la referencia que hace de que el escribano la reconoció con asistencia del corregidor, la primera autoridad civil de la Villa. Dada la situación de la inscripción se debió colocar un andamio a su altura para poder leerla en detalle, lo cual obligaría a pedir permiso al corregidor para hacer este montaje, que probablemente pudo conllevar la interrupción del tráfico en dicha puerta, lo cual de nuevo conllevaba la intervención de la autoridad gubernativa. Pues el coste monetario, el trabajo previo para hacer el reconocimiento, la intervención del corregidor, todo lleva a pensar que esto no fue un simple encargo académico por parte de un erudito que quisiese estudiar la historia de la villa, aún cuando el solicitante fuese miembro de la Real Academia de la Historia. Más bien podrían pensarse en un tema de índole más administrativa, por ejemplo del señor de la villa, el Duque de Alburquerque, que con este texto podría demostrar que las murallas y castillo de la Villa habían sido realizadas por el señor del lugar en ese momento, y que como herederos de este señorío los actuales Duques podrían tener determinados derechos económicos y militares que estarían reivindicando dentro del contexto de la defensa general del Reino, que estaba sufriendo transformaciones, ya hemos visto que por su situación estratégica, Alburquerque va a estar calificada como plaza de armas y con una guarnición formada por ocho compañías de milicias urbanas ${ }^{45}$ cuyo Comandante era el Gobernador de la Plaza. La verdad es que no podemos saberlo, sólo decir que el coste económico, de trabajo y de tiempo de realizar esta acta fue relativamente importante ${ }^{46}$.

45 En el Estado Militar de España de 1784 se informa que las Milicias Provinciales empezaron a crearse en 1734, y también se citan las Milicias Urbanas, que se crearon a partir de 1762.

46 Aunque las inscripciones no poseen el valor jurídico que sí tienen los documentos, resulta evidente su valor probatorio y testimonial como se puede ver claramente en otros ejemplos, siendo uno de los más destacados el de la iglesia de Santianes de Pravia, donde a mediados del siglo XVII Fernando de Salas, cacique local, trató de derribar la antigua capilla mayor para convertirla en el lugar de enterramiento de su familia y cuyas 
Pasemos ahora a comentar específicamente el texto de la transcripción que nos da el Acta Notarial. Como luego veremos no tiene nada que envidiar a los realizados posteriormente, es más demuestra el magnífico conocimiento de los escribanos públicos en la lectura de "escrituras antiguas", lo cual es lógico ya que los documentos medievales seguían vivos administrativamente y debían ser consultados para revindicar los derechos de sus poseedores, por tanto el escribano no tenía problema alguno en leer, en este caso caracteres góticos.

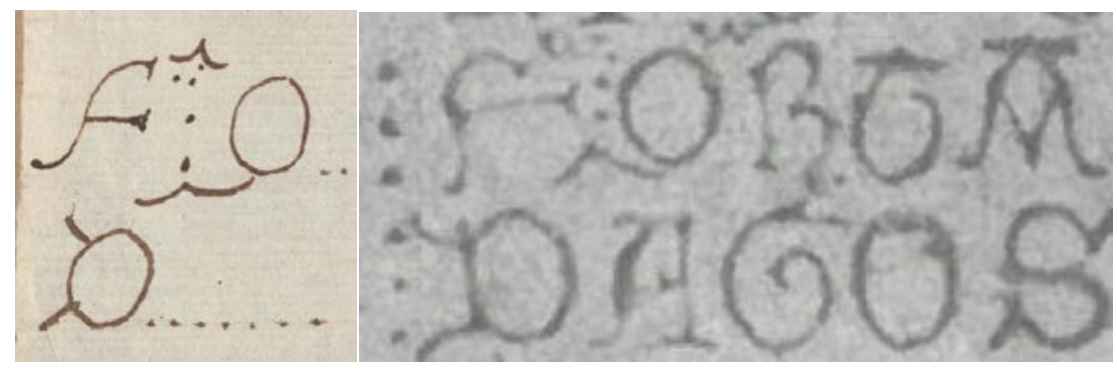

Figura 14. Imagen de la salva del Acta y de la Inscripción.

En segundo lugar hay que decir que el escribano no se limitó a realizar una copia imitativa, sino que ésta fue revisada a conciencia, y en varias ocasiones, como puede verse en dos retoques o añadidos que pueden verse al final de la sexta línea o en la mitad de la novena. Pero además, antes de terminar su trabajo añadió:

intenciones encontraron la oposición de los vecinos, quienes se valieron de una inscripción fundacional del rey Silo para truncar sus intenciones y demostrar el origen real del edificio (Gimeno Pascual; del Hoyo, 2012: 13-26) (Rico Camps, 2014: 82). Son también muy conocidos los casos de copias epigráficas de documentos, ya que mientras que los documentos permanecían en los archivos inaccesibles para el público general, una copia epigráfica de los mismos podía exponerse de forma pública para que su contenido fuera por todos conocido y pudieran tener una garantía de que accedían a las posibles "gracias” concedidas por el documento original, un ejemplo clásico es el de la bula del papa Gregorio XI sobre el reconocimiento de la basílica de San Juan de Letrán como primera iglesia del mundo. En la fachada de este templo, dedicado al Salvador y a San Juan Bautista y San Juan Evangelista, aparece una inscripción que recuerda a los peregrinos que este templo es considerado como la madre de todas las iglesias; "SACROSANCTA LATERANENSIS ECCLESIA OMNIUM URBIS ET ORBIS ECCLESIARUM MATER ET CAPUT”. Los papas vivieron en el Palacio Laterano hasta principios del siglo XIV, cuando abandonaron Roma para trasladarse a Avignon. Durante este exilio en Francia la basílica fue totalmente destruida por un incendio (1308) y el papa Clemente V (1305-1314) ordenó su reconstrucción, pero antes de concluirse un nuevo incendio la asoló en 1360. Entonces el papa Urbano V (13621370) comisionó a Giovanni Stefano para que reiniciara las obras de reconstrucción. En estos complicados tiempos para esta basílica el papa Gregorio XI (1370-1378) decidió renovar y confirmar de forma solemne todas las prerrogativas de dicha iglesia, incluido su rango de primera iglesia de la Cristiandad (Avignon, día X de las Kalendas de febrero, año segundo del pontificado de Gregorio XI, 23 de enero de 1372), y ese documento solemne que estaba custodiado en el archivo de la basílica fue copiado literalmente en piedra (incluso manteniendo la disposición formal del mismo y dibujando al final el sello papal, la famosa bula de plomo que daba validez legal al mismo) para que los fieles pudieran verlo y animarse a hacer donativos que les proporcionaban determinados beneficios espirituales. Existen más ejemplos de este tipo, en España es muy conocido el Decretum indulgentiarum del obispo de León don Pedro Cabeza de Vaca (27 de marzo de 1456), por el cual concedía cuarenta días de perdón a todos los que celebrasen los sábados la vigilia ante la imagen de la Virgen Blanca o diesen limosna para celebrarlas, el documento original con valor jurídico estaba en el archivo de la catedral, pero para que todos los peregrinos conocieran esta posibilidad de obtener indulgencias se colocó una inscripción en el pórtico central de la catedral, junto a la puerta de entrada. Por todo ello creemos que este valor testimonial debe ser con gran probabilidad el motivo que propició la elaboración del acta notarial que nos concierne. 
"Y asimismo zertifico doi fee: como uno de los renglones o linias de dicha inscripcion / principia con la letra $\mathrm{F}$ a la que le siguen los tres puntos y después otra / letra que paresce $\mathrm{O}$ y el renglon siguiente ${ }^{47}$ principia con una $\mathrm{D}$ en la conformidad que se demuestra al margen de forma que una birgula / que esta porsima de la D y finalisa inmediata a la dicha letra $\mathrm{O}$ no puedo a punto fijo afirmar si hera palo de la letra O para / que se haga Q o si hera abreviatura de la D pues le falta la letra E que le deve seguir".

La duda del escribano podría parece lógica, aunque al final la resuelve el contexto y la lectura, F(eri)a Q(ua)RTA al inicio del renglón quinto, y DAGOSTO en el sexto. En cualquier caso, el escribano hizo un trabajo muy detallado, lo repasó a conciencia, cambiando lo que consideraba erróneo (colocando añadidos) y además haciendo una addenda sobre la posible duda que tenía en la interpretación del inicio de los renglones quinto y sexto.

Como hemos podido ver, el escribano que hizo el Acta Notarial realizó una imitación casi exacta del ductus de la escritura de la inscripción, demostrando un perfecto conocimiento del sistema gráfico gótico, sin reflejar grandes diferencias con las recientes lecturas de Sousa (1945 y 1953) y Barroca (2000), lo que habla bien a las claras de su excelente preparación en la "lecturas de escrituras antiguas", como se decía entonces.

\section{Nueva Lectura y edición de la inscripción}

Finalmente, consideramos oportuno ofrecer uma nueva propuesta de lectura de la inscripción desde los critérios metodológicos del Corpus Inscriptionum Hispaniae Mediaevalium (García Lobo; Martín López, 1995) y que condense toda la información proporcionada por el análisis exhaustivo de la historiografía previa, permitiéndonos así dar una respuesta a las dificultades de lectura que se han encontrado en ella.

1306, 4 de agosto

Roboratio y suscriptio de la muralla de Alburquerque ${ }^{48}$.

A. BADAJOZ, Museo Arqueológico de Badajoz, anteriormente estuvo situada sobre la puerta de San Mateo o de la Villa en la muralla de Alburquerque, ocupando hoy su lugar en dicho emplazamiento una réplica. Lápida de mármol cuadrangular de dimensiones desconocidas. La inscripción está organizada en quince líneas que se disponen por todo el campo epigráfica y se encuentran

47 Son los inicios de los renglones cinco y seis

48 Aunque en el proyecto del Corpus la tipología de esta inscripción es la denominada Roboratio, ya que aparece de forma explícita el nombre de la persona que encarga el edificio, podríamos también denominarla monumentum aedificationis, ya que la única diferencia entre ambas tipologías es la presencia o no del nombre de la persona antes comentada, pero ambas tipologías tienen el mismo sentido (Martín López; García Lobo, 2009: 192-193). 
separadas en la parte central del texto por el escudo de armas de Alfonso Sánchez. En un módulo menor, aparece ejecutada una segunda inscripción debajo del escudo, dispuesta en tres líneas. Escritura gótica mayúscula. Buen estado de conservación.

a. Roboratio

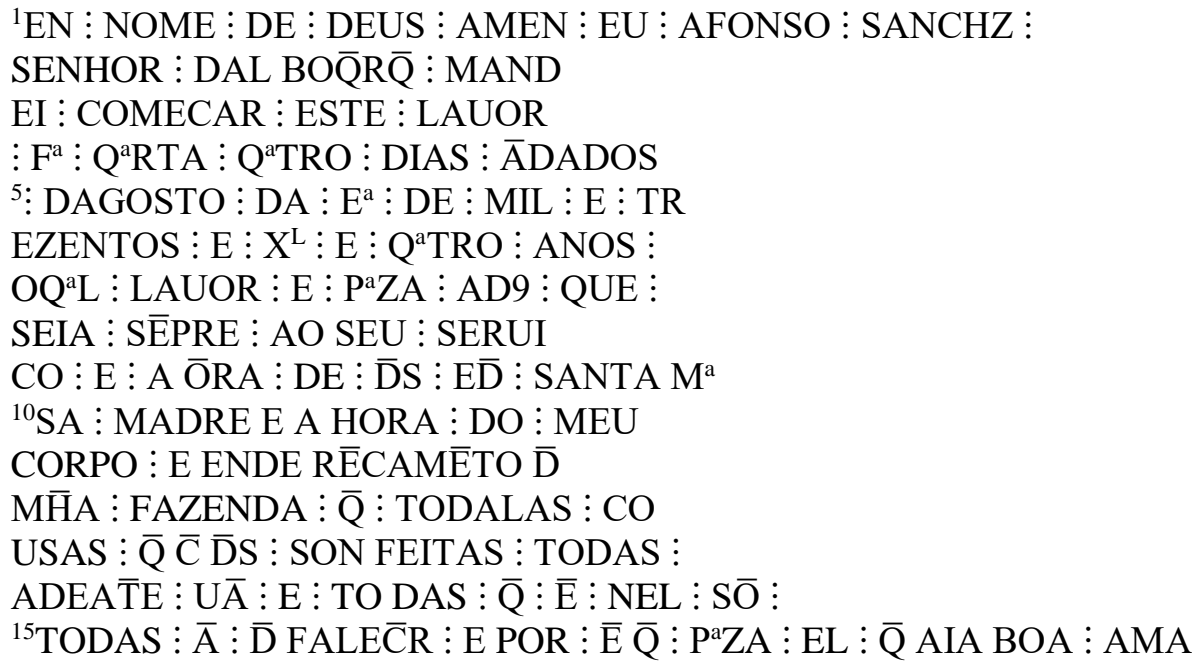

En nome de Deus, amen. Eu A(l)fonso Sánch(e)z / senhor dAlboq(ue)rq(ue), mand / ei comecar este lavor / f(eri)a q(u)arta, q(u)atro dias a(n)dados / dagosto da e(r)a de mil e tre / zentos e XL e q(u)atro anos. / O q(u)al lavor e p(r)aza a $D($ eus) que / seia se(m)pre ao seu servi-/ co et a (h)o(n)ra de D(eu)s e d(e) Santa M(ari)a, / sa madre e a ho(n)ra do meu / corpo e ende re(n)came(n)to d(e) / m(in)ha fazenda q(ue) todalas co-/ usas q(ue) c(om) d(eu)s son feitas, todas / adea(n)te va(n) e todas q(ue) e(m) nel so $(m) /$ todas $a(m) d(e)$ falec(e)r. E por e $(m)$ q(uem) p(r)aza el q(ue) aia boa ama.

En el nombre de Dios, amén. Yo Alfonso Sánchez, señor de Alburquerque, mandé comenzar esta obra la feria cuarta, a cuatro días andados de agosto de la era de mil trescientos cuarenta y cuatro años. Dios quiera que esta obra esté siempre a su servicio y para honra de Dios y de Santa María su madre, y para honra de mi cuerpo y beneficio de mi hacienda. Pues todas las cosas que con Dios son hechas, todas prosperan y todas las que son sin él han de perecer. Y por ello, quiera que se haga con buena estima.

b. Suscriptio

${ }^{1} \mathrm{EU} ! \vdots:$ PEDR

$\overline{\mathrm{O}} \vdots \mathrm{U}^{\mathrm{E}} \vdots \mathrm{M}^{\mathrm{E}} \vdots \mathrm{DE} \vdots \mathrm{ES}$

TE $:$ CAS TELLO $:^{\prime} \overline{\mathrm{F}}^{\prime}$ 
Eu pedr(eir) / o? V(icent)e? m(aestr)e de es / te castello, fiz.

Yo, el cantero Vicente, maestre de este castillo, lo hice.

\section{Conclusiones}

En definitiva, destacamos el Acta Notarial de 1747 como un documento excepcional desde el punto de vista de la información en él mostrada y la forma en la que se expone, donde muestra el buen conocimiento de los escribanos de las llamadas entonces "escrituras antiguas", que le permitió hacer una copia imitativa de gran calidad.

Desafortunadamente, desconocemos los motivos concretos que llevaron a su creación, así como la personalidad de quién ordenó su realización o cómo llegó a la Colección Litológica de la Real Academia de la Historia. Si bien, este desconocimiento no le resta importancia como testimonio del valor documental que poseían las inscripciones, especialmente en un contexto en el que toman consideración como fuente de primer orden para la reconstrucción del pasado y también con cierto valor probatorio y jurídico.

Las inscripciones, cuyo principal objetivo y razón de ser es la publicidad, es decir la difusión de eventos, hechos o ideas a un público amplio, poseen también un innegable valor documental y testimonial cuando a través de ella se da noticia y se comunican acciones determinadas, como en este caso el referente a la construcción de la muralla y el papel de Alfonso Sánchez como patrón y promotor de las obras. Algo que sin duda los eruditos del siglo XVIII conocían, por lo que no nos parecería desacertado pensar que el origen y motivo de la elaboración del Acta Notarial guarde algún tipo de relación con este concepto, importante tanto para el entonces señor de la villa, el duque de Alburquerque, como para los miembros del gobierno de la misma, que por esas fechas participaron en la realización de varios cuestionarios históricos que servirían de base a obras históricas.

Del mismo modo, el estudio de este Acta Notarial nos ha abierto la puerta al análisis de la historiografía de la inscripción, analizando cómo el texto y la imagen unida a ella (el escudo heráldico), se ha ido transmitiendo entre los diferentes autores, y también los problemas de lectura e interpretación que ha generado. Un trabajo que sin duda ha de ser siempre tenido en cuenta por parte de la ciencia epigráfica, especialmente para la reconstrucción de los textos epigráficos desaparecidos o en mal estado de conservación. El cual no ha de ser realizado atendiendo exclusivamente a la inscripción propiamente dicha, sino a todos los elementos que la componen y participan de ella, tal y como hemos podido demostrar con la errónea transmisión del escudo de armas por los diferentes autores, lo cual nos aporta un dato sobre la credibilidad de los mismos, ya que si describen mal el escudo es casi seguro que no vieron directamente la inscripción, sino que tomaron los datos de ella de forma indirecta. Gracias a ello, hemos podido ofrecer en estas líneas una lectura de la inscripción que atienda a todos sus elementos, a saber, internos, externos y funcionales, que nos permite conocer con mayor exactitud el sentido original de la 
inscripción, que creemos formaba parte de todo un programa epigráfico, como se aprecia al comentar las inscripciones que se relacionaban con la que estamos estudiando.

De este modo, hemos podido determinar la existencia de dos inscripciones en el mismo soporte, que fueron ejecutadas, aunque muy cercanas en el tiempo, en momentos diferentes y con objetivos diferentes: en primer lugar, la roboratio creada por voluntad de Alfonso Sánchez para dar noticia de su actuación en las nuevas construcciones de la villa y, en segundo lugar, la suscriptio ejecutada por el rogatario de la primera inscripción al utilizar un espacio en blanco creado inintencionadamente como resultado de la mise en page y que aprovecha para dar a conocer su personalidad como autor material de la inscripción.

\section{Referencias Bibliográficas}

Abrantes, M. de (Luis Gonzaga de Lancastre e Távora) (1982). “Anmotamentos de armaria medieval portuguesa: a Bandeira heráldica de D. Afonso Sanches”, Arquivo de Cascais: boletim cultural do municipio, n4, 79-90.

Abrantes, M. de (Luis Gonzaga de Lancastre e Távora) (1983). O estudo da sigilografia medieval portuguesa. Lisboa.

Alberola Fioravant, M. V. (1995). Guía de la Biblioteca de la Real Academia de la Historia. Madrid.

Arbor Aldea, M. (2005). Don Afonso Sanchez. Notas biográficas, en Actas del IX Congreso Internacional de la Asociación Hispánica de Literatura Medieval (La Coruña, 18-22 de septiembre de 2001), La Coruña, pp. 315-330.

Argote de Molina, G. (1588). Nobleza del Andaluzía.

AA. VV. (1944). Memorias de los Museos Arqueológicos Provinciales 1943. Madrid.

AA. VV. (1994). Interrogatorio de la Real Audiencia de Extremadura de 1791 en Extremadura a finales de los tiempos modernos. Partido de Badajoz. Mérida, Asamblea de Extremadura.

Barrientos Alfageme, G. (1991). Estremadura por López. Año de 1798. Mérida.

Barroca, M. J. (2000). Epigrafía medieval portuguesa: 862-1422. Lisboa.

Bezerra, M. G. de L. (1785-1791). Os Estrangeiros no Lima. Coimbra.

Brandao, F. de (1672). Monarquia Lusitana. Parte VI. Lisboa.

Brás de Albuquerque, A. (1557). Commentarios do Grande Afonso de Albuquerque capitão geral \& gouernador da India, colligidos... das proprias cartas que elle escreuia ao muyto poderoso Rey Dõ Manuel, o primeyro deste nome. Lisboa.

Brás de Albuquerque, A. (1576). Commentarios do Grande Afonso Dalboquerque, Capitam Geral que foy das Indias Orientaes, em tempo do muito poderoso Rey dom Manuel, o primeiro desde nome. Novamente emendados \& acrescentados pelo mesmo auctor, conforme as informaçoes mais certas que agora teve. Lisboa.

Cabrera Gallardo, A. (1933). Para la Historia de la noble villa de Alburquerque. Toledo.

Delgado Serrano, A. (1950). Piedras armeras del Museo Arqueológico de Badajoz. Memorias de los Museos Arqueológicos Provinciales 1948-1949 (extractos), vol. IX-X, pp. 10-12.

Duarte Insúa, L. (1929). Historia de Alburquerque. Badajoz.

García Lobo, Vicente; Martín López, E. (1995). De Epigrafía medieval. Introducción y Álbum, León. 
Gimeno Pascual, Helena; Hoyo, J. del (2012). La Epigrafía medieval asturiana. Los epígrafes de la Iglesia de San Juan de Santianes de Pravia, en Asturas entre visigodos y mozárabes, Madrid, pp. 13-26.

Jesús María José, P. de (1754-1760). Chronica da Santa e Real Província Immaculada Conceiçao de Portugal, da mais Estreita e Regular Observância do Serafim Chagado S. Francisco... Tomo II. Lisboa.

López, T. Diccionario Geográfico de España, Extremadura. (BNE Mss/7299).

Madoz, P. (1846). Diccionario Geográfico-Estadístico-Histórico de España y sus posesiones de Ultramar. Tomo II. Madrid.

Maier Allende, J. (2011). Noticias de Antigüedades de las Actas de Sesiones de la Real Academia de la Historia (1738-1791). Madrid.

Martín López, E.; García Lobo, V. (2011). La epigrafía medieval en España. Por una tipología de las inscripciones, en VIII Jornadas Científicas sobre Documentación de la Hispania altomedieval (siglos VI-X). Madrid: Universidad Complutense, 185-213.

Martín López, E.; García Lobo, V. (2012). Impaginatio en las inscripciones medievales. León.

Mélida, J. R. (1926). Catálogo Monumental de España, Provincia de Badajoz (1907-1910). Madrid.

Menéndez Pidal de Navascués, F. (1993). Los emblemas heráldicos, una interpretación histórica. Discurso de ingreso en la Real Academia de la Historia. Madrid, Real Academia de la Historia.

Menéndez Pidal de Navascués, F. (2014). Los emblemas heráldicos, novecientos años de historia. Sevilla, Real Maestranza de Caballería de Sevilla.

Nava Rodríguez, T. (2020). «Francisco de Rivera», en Real Academia de la Historia, Diccionario Biográfico electrónico. http://dbe.rah.es/biografias/23772/francisco-derivera [Consulta 21/02/2020].

Nava Rodríguez, T. (2020). «Antonio Mateos Murillo», en Real Academia de la Historia, Diccionario Biográfico electrónico. http://dbe.rah.es/biografias/20234/antonio-mateosmurillo [Consulta 21/02/2020].

Pinho Leal, A. de (1873-1890). Portugal antigo e Moderno... Vol. IV. Lisboa.

Rico Camps, D. (2014). Inscripciones monumentales del siglo VIII (de Cangas a Pravia). Territorio, Sociedad y Poder, 9, 67-98.

Rivera, F. de (1779). Tablas que reducen á reales y maravedís de vellón la moneda antigua de oro, y la del nuevo sello, y su correspondencia, con el aumento que ha dado á una y otra la Real Pragmática de 17 de julio de este año... Madrid. http://bibliotecadigital.jcyl.es/es/consulta/registro.cmd?id=4071 [Consulta 27/02/2020].

Salazar y Acha, J. de (2000). La Casa del Rey de Castilla y León en la Edad Media. Madrid.

Sousa, A. C. de (1783). História genealógica da Casa Real Portugueza. Tomo IV y V. Lisboa.

Sousa, J. M. C. de (1945). Dos inscripciones portuguesas en España. Boletín de la Real Academia de Buenas Letras de Barcelona, XVIII, 245-249.

Sousa, J. M. C. de (1946). Dos inscripciones portuguesas en España y un problema epigráfico. Revista de Estudios Extremeños, 4 (2), 449-460.

Sousa, J. M. C. de (1947). Um problema epigráfico. Revista de Guimarães, LVII, 153-164.

Sousa, J. M. C. de (1953). Duas Inscrições Portuguesas em Espanha (A questão da data das lápidas do castelo de Albuquerque). O Arqueólogo Português, Nova Série (2.a), II, 261-282.

Tarouca, C. da S. (1960). Historia da Raça - História da Familia II. Brotéria. Revista Contemporânea de Cultura, 30, 181. 